\title{
O PROGRAMA DE UMA EPISTEMOLOGIA EVOLUTIVA
}

An evolutive epistemology program

Paulo Abrantes*

\section{Resumo}

Este artigo tem por objetivo explicitar as motivações do programa de uma epistemologia evolutiva e discutir críticas que são tradicionalmente feitas a ele. Inicio apresentando as motivações históricas do darwinismo em biologia e indicando que essas mesmas motivações podem ser vistas orientando alguns programas em psicologia. Passo em seguida a caractenizar três tipos de explicação que podem ser propostas para as adaptações propriamente epistemológicas: o providencialismo, o instrucionismo e o selecionismo. Este último tipo constitui uma formulação mais abstrata da explicação proposta por Darwin para a origem e a evolução das espécies biológicas. A título de ilustração apresento, em seguida, as formulações clássicas de epistemologias selecionistas propostas porPoppere Campbell. Questiono então em que medida epistemologias como a de Campbell podem ser enquadradas na conhecida distinção que propôs Bradie entre uma epistemologia evolutiva de mecanismos e uma epistemologia evolutiva de teorias. Ao final, apresento algumas das objeções mais contundentes que são feitas às epistemologias selecionistas e mostro de que modo elas podem ser respondidas no âmbito do programa selecionista. Concluo apontando algumas das deficiências e limitações do programa no estágio em que se encontra atualmente. Elenco, então, um conjunto de tópicos a serem investigados de modo a eliminar alguns obstáculos ao desenvolvimento do programa selecionista em epistemologia e em outras áreas.

Palavras-chave: evolução, teoria do conhecimento, naturalismo, providencialismo, selecionismo, instrucionismo, Darwin, Popper, Campbell, Dennett.

* Professor da Universidade de Brasília

E-mail: abrantes@unb.br

Revista de Filosofia, Curitiba, v. 16 n.18, p. 11-55, jan./jun. 2004. 


\section{Abstract}

The aim of this paper is to make explicit the motivations of the program of an evolutionary epistemology and to discuss critiques that have been traditionally made to it. I start by presenting the historical motivations of darwinism in biology and I suggest that the same motivations can be seen as guiding some programs in psychology. Next I characterize three types of explanations that can be proposed to adaptations properly epistemological: providentialism, instructionism and selectionism. The last type corresponds to a more abstract formulation of the explanation proposed by Darwin for the origin and evolution of biological species. As an illustration, I present next the formulations, now classical, of selectionist epistemologies, proposed by Popper and Campbell. I address the question of the applicability of Bradie's distinction between an evolutionary epistemology of mechanisms and an evolutionary epistemology of theories, to an epistemology as the one proposed by Campbell. At the end I discuss some of the most significantcritiques that have been addressed to selectionist epistemologies and I show how they can be faced from within the selectionist program. I conclude by pointing to some of the shortcomings of the program in its present configuration. I list a set of topics to be investigated in order to circumvent some of the obstacles to the development of the selecionist program in epistemology and in other domains.

Keywords: evolution, theory of knowledge, naturalism, providencialism, selectionism, instructionism, Darwin, Popper, Campbell, Dennett.

\section{Motivações do darwinismo em biologia}

Darwin estendeu o âmbito das explicações naturalistas e mecanicistas - que, gradualmente, tornaram-se hegemônicas a partir do séc. XVII naquelas ciências que têm por objeto o mundo inanimado - de modo a incluir sistemas complexos e adaptativos, como os organismos vivos.

A seleção natural constitui uma explicação naturalista (em lugar de sobrenaturalista) para as adaptações reveladas pelos seres vivos, tanto em sua estrutura anatômica e organização funcional, quanto em seu comportamento. Os projetos dos organismos e as funções que desempenham as suas várias partes são explicados, desse modo, sem se apelar

Revista de Filosofia, Curitiba, v. 16 n.18, p. 11-55, jan./jun. 2004. 
para qualquer tipo de providencialismo, para o que Dennett (1995) chamou de skyhooks - que poderíamos traduzir por 'ganchos presos ao céu'. Com a seleção natural, Darwin descobriu um modo de explicar a complexidade adaptativa sem pressupor a intervenção milagrosa de alguma inteligência que fizesse o papel de projetista.

A seleção natural pode, ao mesmo tempo, ser vista como uma explicação mecanicista (ou mecanística) das adaptações observadas nos seres vivos. ${ }^{1}$ As explicações teleológicas (que apelam para causas finais) - que foram tradicionalmente propostas para os fenômenos do mundo animado, para a origem, desenvolvimento e funcionamento dos seres vivos - puderam, desse modo, ser rejeitadas também pela biologia.

Antes de prosseguir, convém recapitular, brevemente, o que distingue a evolução darwinista da evolução lamarckista. ${ }^{2}$

Na evolução lamarckista, o indivíduo adapta-se ao meio ambiente durante o (relativamente curto) lapso da sua existência. O organismo transmite, então, as características adquiridas aos seus descendentes. A causa da variação adaptativa é, de forma direta, o meio ambiente. Este 'instrui' (informa) o organismo sobre como aumentar a sua adaptação.

Usando-se (anacronicamente, é claro) os conceitos da genética, seria lamarckista a tese de que modificações no fenótipo (como conseqüência de suas interações com o meio ambiente) causam mudanças no genótipo, sendo dessa forma transmitidas para a descendência. A informação 'flui' do meio ambiente para o fenótipo, e deste para o genótipo. É nesse sentido que se deve entender a tese de que, no lamarckismo, o meio ambiente instrui o organismo a respeito das modificações (variações) que são adaptativas (configurando uma ortogênese ${ }^{3}$ ). Ainda uma

1 Embora mecanística, a explicação com base na seleção natural apresenta características diferentes das explicações mecânicas típicas propostas por outras ciências naturais, como a física, por exemplo. Não explorarei esse tópico, que foge ao escopo do artigo.

2 Não estou aqui preocupado em ser fiel, historicamente, ao modo como Darwin e Lamarck formularam as suas teorias, mas sim numa tradução mais abstrata de suas contribuições, enquanto duas modalidades distintas de se explicar um processo evolutivo. É importante, nesse contexto, distinguir a evolução (por exemplo, das espécies biológicas) enquanto fato, das explicações que podem ser propostas para esse fato. A minha ênfase é, aqui, em distinguir tipos de explicação para a evolução, e não em fornecer evidências a favor da existência de processos evolutivos.

3 A ortogênese corresponde à tese de que as variações se dão em direções que garantem a adaptação do indivíduo ao meio ambiente.

Revista de Filosofia, Curitiba, v. 16 n.18, p. 11-55, jan./jun. 2004. 
outra maneira de dizer isso seria: no lamarckismo há 'acoplamento' entre as variações e as pressões seletivas ambientais.

Na evolução darwinista, por sua vez, a fonte ou causa da variação adaptativa não é o meio ambiente, que simplesmente exerce o papel de selecionar as variações geradas, digamos, autonomamente, 'cegamente' (ou seja, de modo não informado) pelos sistemas biológicos (ver fig. 1). As variações não são, portanto, instruídas (direcionadas) pelo meio ambiente. Há 'desaclopamento' entre os mecanismos de seleção e de variação. Em outras palavras, a geração de variações não está correlacionada com informações a respeito do que pode ou não ser útil ao sistema, informações a respeito de possíveis soluções para os seus problemas adaptativos. O darwinismo, ao defender que o processo de variação é 'cego', rejeita, portanto, a ortogênese.

No darwinismo (permitindo-me, de novo, ser anacrônico) as modificações fenotípicas (que ocorrem ao longo da vida de um organismo individual, na sua ontogênese) não causam, diretamente, mudanças no genótipo. A informação não flui do meio ambiente para o fenótipo, e deste para o genótipo, como no lamarckismo.

Indiretamente, é claro que também na evolução darwinista o meio ambiente possui um papel central em afetar a distribuição estatística dos genes em uma certa população (ou seja, na filogênese). Mas, isso se dá pela seleção dos fenótipos - ou, se quiserem, dos organismos (seres vivos) individuais - que funcionam como veículos para certos genótipos. São os fenótipos que interagem causalmente com o meio ambiente externo e não os genótipos. Os fenótipos são selecionados em função do seu maior ou menor grau de adaptação que condiciona, por sua vez, o seu potencial de reprodução. Quanto mais descendentes deixa o organismo, maior é a participação dos seus genes na distribuição genética da população.

Para o darwinismo não há adaptação ideal, absoluta, de um organismo. A adaptação de um ser vivo é sempre local, relativa a um meio ambiente particular. Se houver mudanças nas características do meio ambiente, o organismo pode não mais se revelar adaptado. Tampouco há progresso na evolução, ou seja, uma linha ascendente, como acreditava Lamarck. Por outro lado, no darwinismo a evolução tem um caráter estatístico: temos que falar sempre de populações e da distribuição de características em uma população, o que dificulta a comparação com uma con-

Revista de Filosofia, Curitiba, v. 16 n.18, p. 11-55, jan./jun. 2004. 
cepção lamarckista de evolução. A evolução darwinista se expressa na população, e não no desenvolvimento de um indivíduo particular.

Resumindo, as distinções entre os dois tipos de evolução (ou, melhor, entre tipos de explicação para adaptações) podem ser feitas com base:

a) na direção em que flui a informação;

b) no mecanismo de variação (se cego ou não; se há ou não acoplamento entre variação e pressão seletiva);

c) no papel que desempenha o meio ambiente em cada tipo de evolução (se instruindo ou selecionando).

A explicação darwinista para a evolução (que postula o que chamarei, doravante, de 'processo seletivo') envolve três subprocessos: variação, seleção e transmissão (ou retenção de características).

As explicações propostas por Lamarck para a 'evolução' dos seres vivos foram, sem dúvida, um avanço em direção ao mecanicismo. ${ }^{4}$ Mas, além de se comprometer com a ortogênese - ou seja, com a idéia de uma direção na evolução dos seres vivos -, ele não explica porque as modificações ocorridas no indivíduo, durante o seu desenvolvimento, devam ser adaptativas. Apelar para uma instrução do meio ambiente - que indicaria, de algum modo, como o organismo deve modificar-se para se tornar mais adaptado - pode ser visto como tão insatisfatório quanto as explicações providencialistas, levando autores como Cziko (1995) a avaliar que, no contexto do instrucionismo, as adaptações também resultam de 'milagres'. Além disso, Lamarck não explicou como as modificações, supostamente adaptativas, são transmitidas para a descendência. ${ }^{5}$

4 Lamarck manteve, contudo, seus compromissos providencialistas (sobrenaturalistas): os organismos têm uma adaptação perfeita ao meio ambiente por terem sido projetados por Deus. Lamarck acreditava que há uma tendência, inata a todos os seres vivos, de ascenderem na escala de complexidade e de perfeição. Também teria origem divina a tendência progressiva que acreditava haver na 'evolução' dos seres vivos. Por tais conotações, Darwin preferiu não usar o termo 'evolução' na Origem das Espécies, mas sim a expressão 'descendência com modificação'. A noção de evolução, como a utilizamos hoje em dia, tem o seu significado ligado ao processo darwinista de seleção natural. Seu uso no contexto lamarckista só pode, atualmente, ser metafórico, daí o uso que faço de aspas quando falo de 'evolução' neste contexto.

5 É preciso reconhecer que Darwin também nunca chegou a uma explicação aceitável para a hereditariedade e não teve conhecimento dos trabalhos de Mendel, que só foram redescobertos no séc. XX.

Revista de Filosofia, Curitiba, v. 16 n.18, p. 11-55, jan./jun. 2004. 
Por fim, o caráter revolucionário da explicação darwinista para a complexidade adaptativa pode também ser percebido no modo como evita cometer 'petição de princípio', ou seja, a falácia de assumir (de modo, em geral, implícito) justamente aquilo que se pretende explicar. Seria cometer petição de princípio, no caso, pressupor um sistema com igual ou maior complexidade adaptativa que o sistema a ser explicado. Ou ainda, invocar algum conhecimento prévio ('pré-ciência', previdência ou antevisão), cuja origem não é elucidada, para explicar as adaptações reveladas pelos organismos. ${ }^{6}$

A partir dessas distinções fundamentais entre o darwinismo e 0 lamarckismo em biologia, podem-se articular dois tipos abstratos de explicação - conhecidas como 'selecionismo' e 'instrucionismo', respectivamente - que são abstratas por não fazerem referências diretas a propriedades ou processos biológicos. Essas formulações abstratas podem ser utilizadas como modelos para explicar fenômenos adaptativos em outras áreas, como a psicologia e a epistemologia ${ }^{7}$.

\section{Motivações do selecionismo em psicologia}

Uma rápida incursão em processos simples de aprendizagem talvez possa melhor elucidar a distinção entre instrucionismo e selecionismo enquanto tipos abstratos de explicação para adaptações em geral. Acredito que também ilustre a motivação de não se admitir petição de princípio, que leva a adotar uma explicação de tipo selecionista para fenômenos adaptativos.

Pode-se ver a aprendizagem como um processo no qual os padrões comportamentais exibidos por um indivíduo (organismo, sistema cognitivo, etc.) tornam-se gradualmente mais adaptados às condições do meio ambiente em que se situa.

Considere-se a diferença entre o condicionamento operante e 0 pavloviano. Neste último, o indivíduo que apresenta um determinado

6 As motivações naturalista, mecanicista e de se evitar petição de princípio nas explicações não são motivações de todo independentes, mas se relacionam de muitas maneiras, como deve ter transparecido nas discussões que faço nesta seção. Mas acredito ser instrutivo discutir, separadamente, cada uma delas.

7 'Epistemologia' está sendo usado neste texto no seu sentido usual de teoria do conhecimento. 
padrão comportamental diante de um certo estímulo (por exemplo, um cão que saliva diante de um pedaço de carne) aprende a exibir esse mesmo comportamento em resposta a um outro estímulo (por exemplo, o som de uma sineta) que lhe seja apresentado concomitantemente ao estímulo anterior. Desse modo, o indivíduo (e.g. um animal) aprende a responder a um outro estímulo (o som, ou estímulo condicionado) da mesma maneira como respondia ao estímulo anterior (ou incondicionado). Neste caso, pode-se dizer que há uma instrução ao indivíduo pelo meio ambiente, que lhe exibe dois estímulos concomitantemente, de modo análogo ao que ocorre no caso da explicação lamarckista (instrucionista).

O instrucionismo, portanto, pode explicar algumas adaptações comportamentais (como no condicionamento pavloviano), mas não é capaz de explicar a aprendizagem de comportamentos novos e comple$\mathrm{xos}^{8}$. Para tanto, requer-se o outro tipo de condicionamento, operante.

No condicionamento operante, o animal apresenta espontaneamente, aleatoriamente ${ }^{9}$, um dado comportamento que é, em seguida, reforçado ou punido. O comportamento inicial não é causado por um estímulo externo. As condições ambientais somente selecionam o comportamento, tornando-o mais freqüente (pelo reforço) ou menos freqüente (pela punição). Pode-se dizer, de outro modo, que os efeitos do comportamento aumentam a probabilidade de que ele se repita ou a diminuem.

Já Skinner percebera a analogia entre a chamada 'lei do efeito' e a seleção natural darwiniana. ${ }^{10}$ Dennett reforça essa analogia $(1975, \mathrm{p}$. 73): no condicionamento operante, variações nos padrões comportamen

8 Notar que no condicionamento pavloviano o indivíduo não aprende uma nova resposta. Ele aprende a associar uma resposta antiga (ao estímulo incondicionado) a um novo estímulo (condicionado).

9 É uma simplificação afirmar, como faço aqui, que a emissão de comportamentos é aleatória. Distinguirei, adiante, variação 'cega' de 'aleatória', de modo a reconhecer que sempre há uma 'canalização' das variações. Por enquanto, essa simplificação tem o fim didático de aproximar o condicionamento operante de uma modalidade básica de processo seletivo.

${ }^{10} \mathrm{O}$ psicólogo Thomdike foi o primeiro a enunciar esta lei que pode ser formulada, simplificadamente, nos seguintes termos: as respostas comportamentais reforçadas são repetidas com maior freqüência. Skinner, aparentemente, viu mais do que uma simples analogia entre esta lei e a seleção natural darwinista; haveria uma continuidade entre o processo de condicionamento operante e o processo de seleção natural (ver Dennett, 1985, p. 374).

Revista de Filosofia, Curitiba, v. 16 n.18, p. 11-55, jan./jun. 2004. 
tais, apresentados de forma inicialmente aleatória, são selecionadas pelas condições ambientais (ver as 'criaturas skinnerianas' na fig.2). 0 indivíduo, inicialmente, não tem idéia (pré-ciência) dos efeitos do seu comportamento. Não recebe, tampouco, qualquer instrução do meio ambiente a respeito desses efeitos, como é o caso no condicionamento pavloviano.

Dennett vai além e defende que alguma modalidade de selecionismo, em algum nível, pode ser inescapável, necessária para que se explique a aprendizagem sem se cometer petição de princípio. $\mathrm{O}$ mesmo também vale para que se explique, de modo aceitável, qualquer manifestação de inteligência e de criatividade genuínas. Isso porque a explicação selecionista não pressupõe, por exemplo, um conhecimento prévio (das condições ambientais e de como responder adaptativamente a elas) e não comete petição de princípio postulando a existência de homúnculos que guiam o comportamento observado (e que possuem uma inteligência, racionalidade, previdência, etc. cuja origem não é, por seu turno, explicada). ${ }^{11}$

Para se explicar a aprendizagem de comportamentos novos e complexos sem se cometer petição de princípio, é preciso levar em conta dois sub-processos desacoplados: gerar e testar. O condicionamento operante, como vimos, possui essa estrutura: o organismo 'gera' comportamentos e o meio ambiente os 'testa' (seleciona).

No que diz respeito à explicação da criatividade, Dennett toma de empréstimo a Paul Valéry a fórmula: "é preciso dois para inventar qualquer coisa”, um gerador e um seletor (1975, p. 71). O que é gerado pode ser, por exemplo, um comportamento ou uma idéia. Contudo, exige-se que o gerador atue, em última instância, de modo arbitrário, fortuito, aleatório, cego (sem conhecimento prévio) ${ }^{12}$, injustificado, não intencional.

11 Podem-se ver mentes de diferentes tipos e suas propriedades (que podem chegar a caracterizar alguma forma de inteligência) com tendo a função de aumentar a adaptabilidade dos organismos e sua flexibilidade comportamental. Esta tese pode sugerir uma estratégia para se explicar como mentes evoluíram (e os processos cognitivos que as caracterizam). Ver também a nota 20.

12 Até aqui venho utilizando os termos 'aleatório' e 'cego' como praticamente sinônimos, mas veremos adiante que devem ser distinguidos, para uma compreensão adequada da abordagem selecionista.

Revista de Filosofia, Curitiba, v. 16 n.18, p. 11-55, jan./jun. 2004. 
Caso o gerador apresente um grau de clarividência, de conhecimento, de criatividade, de intencionalidade, de inteligência - gerando somente candidatos plausíveis, justificados, por exemplo, comportamentos ou idéias ao mesmo tempo novas e adequadas - isso deve ser explicado por processos seletivos ocorridos previamente. Esses processos seletivos anteriores explicariam como esse conhecimento foi adquirido, seja por aprendizagem ao longo da história ontogenética do indivíduo, seja como resultado de processos seletivos ocorridos ao longo da história filogenética (no caso do conhecimento ser inato). Em outras palavras, exige-se que toda e qualquer adaptação seja explicada. Se esta última supõe alguma adaptação prévia, também tem que ser explicada e assim por diante, até se chegar a um gerador que atue sem qualquer previdência, sem capacidade de escolha, portanto de modo completamente aleatório.

Através dessa série de explicações recursivas de qualquer indício de inteligência (previdência, etc.) chegamos, no limite, a geradores que são meros autômatos. Só isso não basta, evidentemente, para explicar adaptações. O que é gerado tem que ser selecionado por algum 'testador', por um meio ambiente que faz a triagem do que é adaptativo ou não:

"Resumidamente, todo processo de aprendizagem genuína (ou de invenção, que é somente um tipo especial de aprendizagem) deve invocar, em pelo menos um nível, mas provavelmente muitos níveis, 0 princípio de 'gerar-e-testar' " (Dennett, ibid., p. 85-6). ${ }^{13}$

Toda genuína inventividade e aprendizagem envolvem, portanto, um elemento de aleatoriedade e, outro, crítico, de escolha e de "edição". ${ }^{14} \mathrm{O}$ elemento de crítica pode ser distribuído em diferentes proporções entre o gerador e o testador (este último, ou aquele, se apresentando como mais ou menos inteligente e informado). Quanto mais informado, inteligente e intencional for o gerador, mais ele atua como um homúnculo. Mas a inteligência e informação que o homúnculo possuir tem que ser, por sua vez, explicada. E essa explicação, se não quiser cometer

13 Na seção 4-1 discutirei a relação desta tese com a distinção que Dennett faz, em trabalhos mais recentes, entre diferentes tipos de 'criaturas': 'darwinianas', 'skinnerianas', etc.

14 'Genuíno' está aqui adjetivando algo que é inteiramente novo, ou seja, que não pode ser derivado de alguma informação ou conhecimento que o sistema já possuía previamente.

Revista de Filosofia, Curitiba, v. 16 n.18, p. 11-55, jan./jun. 2004. 
petição de princípio, terá que dispensar, em algum nível, qualquer homúnculo, lançando mão somente de um gerador aleatório (de um autômato) e de um seletor. ${ }^{15}$

Dennett insiste que a sedução que exerce o princípio da seleção natural ${ }^{16}$ não se deve, primariamente, a ser ele mecanístico, materialista, mas ao fato de não cometer petição de princípio na explicação das adaptações biológicas (Dennett, ibid., p. 73). O princípio de seleção natural é um modelo disponível para quem está procurando princípios, em outras áreas, que sejam satisfatórios nesse aspecto:

Darwin explica um mundo de causas finais e de leis teleológicas com um princípio que é, com certeza, mecanístico, porém - de forma ainda mais fundamental - completamente independente de 'significado' e de 'propósito'... [o princípio da seleção natural] é uma condição necessária de qualquer entendimento do propósito que não cometa petição de princípio (1975, p. 73).

Dennett separa, portanto, o caráter mecanístico e materialista do processo de seleção natural, do seu sucesso em não cometer petição de princípio. Poder-se-ia encontrar algum processo que não cometesse petição de princípio e que, ao mesmo tempo, fosse não-mecanístico (embora ele ache que isso é pouco provável):

Não é que o nosso preconceito prévio a favor do materialismo nos dê uma razão para aceitar o princípio de Darwin, que é materialista, mas sim que a nossa aceitação prévia da condição de não cometer petição de princípio nos fornece uma razão para adotar o materialismo, uma vez que se percebe que Darwin ofereceu uma explicação materialista para o projeto [design] e o propósito na natureza, que não comete petição de princípio (1975, p. 74).

Embora nesta seção, em que acompanhei algumas colocações de Dennett, haja uma ênfase no comportamento e numa abordagem comportamentalista (behaviorista) é preciso deixar claro que o selecionismo não implica em se adotar esse programa particular em psicolo-

${ }^{15}$ Um caso particular da falácia da petição de princípio é, portanto, a de supor homúnculos para explicar a origem e/ou o funcionamento de mentes.

${ }^{16}$ A minha opção neste texto foi a de utilizar o termo 'processo' em vez de 'princípio', Dennett preferindo este último. Com isso desejo enfatizar não somente que é algo que ocorre no mundo (e não somente um elemento das nossas teorias), mas também os vários sub-processos envolvidos na seleção natural, todos eles necessários para que ocorra a adaptação.

Revista de Filosofia, Curitiba, v. 16 n.18, p. 11-55, jan./jun. 2004. 
gia. ${ }^{17}$ Podemos, também, explorar as capacidades explicativas do selecionismo no que diz respeito aos mecanismos e processos cognitivos, por exemplo. A área da psicologia evolutiva explora essa direção: tais mecanismos e processos seriam adaptações, resultantes de uma evolução a ser explicada pela seleção natural. ${ }^{18}$ Por exemplo, pode-se perguntar como evoluíram as capacidades cognitivas necessárias para que um animal possa aprender, seja com base no condicionamento pavloviano, seja operante. Em ambos os casos, a explicação terá que ser selecionista, e não instrucionista. ${ }^{19}$

\section{Motivações do selecionismo em epistemologia}

Passo, agora, ao caso da epistemologia, que é o objeto deste artigo. O que viria a motivar, nesta área, a adoção de uma perspectiva selecionista? Quais as suas implicações?

Com base nas discussões anteriores, podemos esperar que a tentativa de articular um selecionismo aplicável à epistemologia seja tam

17 Pelo contrário, pode-se defender que uma perspectiva evolutiva contrapõe-se ao ambientalismo extremado dos behavioristas mais ortodoxos, que negam tanto os instintos, e sua base hereditária, quanto o apelo a estados internos para explicar o comportamento animal e humano. Ver, por exemplo, Laland, K. \& Brown, G. (2002).

18 Convém, nesse ponto, ser mais preciso quanto ao sentido estrito em que 'adaptação' será usado doravante. Uma estrutura, processo ou comportamento de um sistema é dito 'adaptado' se preenche uma função para o sistema ou aumenta a sua eficiência em replicar-se. É preciso, por outro lado, distinguir a adaptação (algo já obtido), da adaptabilidade ou capacidade de aumentar a adaptação. Godfrey-Smith ressalta que nem toda explicação 'externalista', isto é, de como o meio ambiente afeta e molda a estrutura e o funcionamento de sistemas, possui um caráter adaptacionista. Para tanto é preciso ver tal estrutura e funcionamento como uma solução útil para o sistema, de problemas colocados pelo meio ambiente. Esta é a perspectiva do selecionismo que, nessa medida, constitui uma modalidade especial de externalismo, distinta, por exemplo, do instrucionismo de tipo lamarckista. Neste último, o meio ambiente imprime diretamente no organismo as mudanças que não têm que ser, necessariamente, úteis para o sistema, adaptativas, funcionais, teleonômicas (Godfrey-Smith, 1998, p. 49-50). Farei, à frente, mais considerações sobre o uso de termos como 'externo' e 'interno' no contexto das explicações selecionistas.

19 Ver, a esse respeito, a seção 4-1 em que apresento não somente a distinção que faz Dennett entre diferentes tipos de 'criaturas', mas também onde aponto para hipóteses a respeito de como tais tipos de criaturas podem ter evoluído.

Revista de Filosofia, Curitiba, v. 16 n.18, p. 11-55, jan./jun. 2004. 
bém motivado por uma postura, ao mesmo tempo, naturalista e mecanicista, além de rejeitar explicações que cometam petição de princípio.

O conhecimento e os processos que o geram são considerados, portanto, fenômenos naturais, a serem explicados lançando-se mão dos mesmos recursos que as ciências utilizam para explicar outros tipos de fenômenos naturais.

Pressupõe-se, além disso, que a epistemologia também lide com 'enigmas' adaptativos, problemas relativos a funções, a projetos, análogos aos problemas adaptativos encontrados em biologia e em psicologia, que mencionei nas seções anteriores. ${ }^{20}$

Campbell, um dos pioneiros a articular um programa selecionista em epistemologia, reconhece, explicitamente, a motivação "metafísica" ou "metateórica" desse programa, em especial no que diz respeito a um compromisso mecanicista: compreender processos que manifestam propósito sem apelar para milagres, sem a introdução de uma "metafísica teleológica" (Campbell apud Bradie, 2001, p. 41).

Bradie traduz a motivação de uma epistemologia evolutiva nos seguintes termos: “... o enigma epistemológico é somente uma extensão natural do enigma biológico..." (2001, p. 49). ${ }^{21}$

Uma motivação naturalista pode também se expressar na tentativa de reduzir propriedades semânticas e epistemológicas, como 'verdade', 'adequação empírica', 'justificação', etc., a propriedades 'naturais' (leia-se, descritas pelas ciências naturais), como as de 'função', 'adaptação', 'aptidão', etc. ${ }^{22}$

${ }^{20}$ Godfrey-Smith (1998) defende a tese de que a função da cognição é lidar com a complexidade ambiental. Os processos cognitivos de alto nível envolvem estados mentais que representam o mundo (por exemplo, crenças). Pode-se estender essa tese e defender que tais representações, elas próprias, e não só os processos cognitivos que as geram, são adaptadas no sentido de desempenharem uma função para 0 sistema cognitivo. Essa função, mais especificamente, seria a de tornar o comportamento do sistema mais plástico e adaptável a mudanças no meio ambiente (físico e biológico).

${ }^{21}$ Esta não é, contudo, a maneira mais adequada de colocar a motivação de uma epistemologia evolutiva, na medida em que, como mostrei no caso da psicologia, muitas outras áreas do conhecimento lidam com enigmas adaptativos e não somente, ou primariamente, a biologia. É mais frutífero ver a explicação selecionista, proposta historicamente por Darwin no domínio biológico, como uma abstração, sem compromissos necessários com uma linguagem biológica ou com entidades e processos biológicos.

22 Sobre as várias facetas do naturalismo enquanto orientação filosófica, ver Abrantes, 1998.

Revista de Filosofia, Curitiba, v. 16 n.18, p. 11-55, jan./jun. 2004. 
3-1. Explicações providencialistas, instrucionistas e selecionistas em epistemologia

Admitamos que o conhecimento seja um fenômeno natural e com características adaptativas - ou seja, que o conhecimento e os processos cognitivos que o geram desempenham uma função para o organismo ou sistema cognitivo. Com base nos tipos de explicação caracterizados anteriormente, podemos também distinguir explicações providencialistas, instrucionistas e selecionistas para adaptações propriamente epistemológicas ou cognitivas.

1. O providencialismo em epistemologia pode ser exemplificado pela teoria platônica do conhecimento como reminiscência (anamnesis). A alma é o repositório de um conhecimento que lhe é inerente, constitutivo, não se colocando a questão da sua origem ou não se buscando uma explicação de suas propriedades adaptativas (e.g. a propriedade do conhecimento ser adequado aos seus objetos).

O conhecimento não é, neste caso, explicado; ele é considerado inato e (milagrosamente) adequado aos seus objetos. No providencialismo, simplesmente postula-se que o agente (ou sistema cognitivo) tem conhecimento, que ele tem crenças que são verdadeiras e que são justificadas.

De modo geral, associa-se ao providencialismo o infalibilismo e o fundacionalismo em teoria do conhecimento. Veremos que essas posições são recusadas pelo selecionismo, e problemáticas no âmbito do instrucionismo.

2. 0 instrucionismo em epistemologia pode ser exemplificado pelo empirismo de Locke. A mente é considerada originalmente como uma tabula rasa e o mundo externo transmite (instrui) o conhecimento pelos sentidos, inscrevendo-o na mente.

Um dos problemas com o instrucionismo em epistemologia está em assumir a confiabilidade dos órgãos dos sentidos e a validade das informações que eles veiculam (caracterizando-as como conhecimento). $\mathrm{O}$ instrucionismo não tem recursos para explicar essas propriedades adaptativas, que se mantêm, assim, milagrosas como no providencialismo. Supõe-se que a instrução por meio da experiência do sujeito (ou sistema cognitivo) garante a adaptação do conhecimento que ele adquiriu ao mundo, aos objetos do conhecimento.

Revista de Filosofia, Curitiba, v. 16 n.18, p. 11-55, jan./jun. 2004. 
O instrucionismo em epistemologia está associado à passividade do sujeito na aquisição do conhecimento: a mente se limita a registrar os dados dos sentidos ou, no máximo, é capaz de associá-los mecanicamente e de induzir generalizações a partir dessa base empírica.

No caso das teorias científicas, particularmente, o empirismo e o indutivismo são claramente insuficientes para explicar os valores cognitivos, as chamadas 'virtudes epistêmicas' que atribuímos às teorias (como, por exemplo, a de serem verdadeiras, adequadas empiricamente, etc.). O famigerado problema da indução, apontado por Hume, pode ser reformulado nos seguintes termos: não há como ter certeza a respeito de crenças obtidas por um processo instrucionista. Se porventura essas crenças são adaptadas aos seus objetos (por exemplo, se configuram um autêntico conhecimento), trata-se de algo fortuito, milagroso, já que essa propriedade não pode ser explicada invocando-se tal processo.

3. O selecionismo em epistemologia assenta-se em uma crítica às abordagens anteriores (providencialista e instrucionista), porque estas não explicam o que deveria ser explicado, ou porque cometem petição de princípio nas explicações que propõem para as adaptações consideradas pertinentes à epistemologia.

É o momento de ser mais específico a respeito de quais são essas 'adaptações pertinentes'. ${ }^{23}$ No que diz respeito à epistemologia, elas podem incluir: a adaptação, a aspectos do meio ambiente físico, dos órgãos envolvidos na cognição (e.g. os órgãos perceptivos), da sua estrutura e funcionamento; a adaptação da atividade cognitiva e de seus produtos aos problemas com que 0 sistema se defronta ${ }^{24}$; a adaptação dos produtos da atividade científica (e.g. teorias) aos valores da comunidade científica, etc.

Menciono, nesta passagem, diferentes processos e entidades que são, por hipótese, adaptadas (ou adaptativas). Além disso, há vários modos de se conceber qual seja o meio ambiente seletivo relevante para cada

23 Inclusive porque a noção de 'adaptação' talvez só faça realmente sentido dentro de um contexto darwinista-selecionista. Ver nota 18.

${ }^{24}$ No caso da cognição de alto nível, as soluções para tais problemas - os produtos da atividade cognitiva - são, tipicamente, representações do mundo observável. Quando tais representações têm o caráter de teorias científicas, elas supostamente podem também se referir a um mundo inobservável. Em ambos os casos, deve-se explicar a adaptação dessas representações mentais aos mundos respectivos (e seus objetos).

Revista de Filosofia, Curitiba, v. 16 n.18, p. 11-55, jan./jun. 2004. 
uma delas. Cada alternativa - cada tipo de adaptação - pode, em princípio, requerer um tipo particular de explicação selecionista. Existem, de fato, várias tentativas de formular epistemologias selecionistas (evolutivas), tendo em vista a explicação de modalidades particulares de adaptações cognitivas.

O que têm em comum é o fato de que rejeitam explicações providencialistas e instrucionistas das adaptações pertinentes ao fenômeno do conhecimento como sendo, na verdade, pseudo-explicações. A explicação com base na seleção natural (descrita de modo abstrato) seria o único tipo de explicação aceitável para adaptações (incluindo as pertinentes à epistemologia) e para o fenômeno resultante: a evolução (no caso, a evolução da cognição e do conhecimento).

Em particular, é característico do programa selecionista, como vimos, que ele rejeite como explicação aceitável, que o conhecimento seja diretamente causado ou informado pelo meio ambiente físico ou qualquer outro tipo de meio ambiente. Em vez do conhecimento ser, portanto, instruído ao sistema cognitivo, por assim dizer, 'de fora para dentro', em um único processo, o selecionismo propõe, como alternativa, dois sub-processos desacoplados - de variação e de seleção - para explicar o conhecimento (e adaptações correlatas). ${ }^{25}$

No selecionismo temos, portanto, um processo em, pelo menos, duas etapas: o agente gera ou emite - de forma autônoma, não instruída 'de fora' - variações cognitivas e o meio ambiente as seleciona (confirmando ou rejeitando cada variação cognitiva, como sendo adequada ou inadequada).

As variações pertinentes à epistemologia podem incluir: variações na estrutura e no funcionamento dos órgãos envolvidos na cognição, percepções, processos cognitivos de alto nível e/ou seus produtos (representações, etc.), comportamentos, métodos etc. Essas alternativas já haviam sido mencionadas acima, quando distingui as adaptações pertinentes à epistemologia. ${ }^{26}$

25 A própria dinâmica cognitiva (modificações nos mecanismos e processos cognitivos) e do conhecimento (produto desses mecanismos e processos) são dinâmicas evolutivas que resultam de processos seletivos. Essas dinâmicas são análogas às que ocorrem na filogênese em biologia. Ver também nota 37.

26 Convém relembrar que as adaptações resultam de várias etapas do processo seletivo, incluindo o de variação. Esta é dita 'cega' justamente porque, ao ser emitida, nada garante que venha a ser adaptativa para o sistema.

Revista de Filosofia, Curitiba, v. 16 n.18, p. 11-55, jan./jun. 2004. 
No caso de representações (e.g. teorias), dizer que são 'adaptadas' pode significar, usando a linguagem tradicional da epistemologia, que são justificadas (confirmadas) ou que são verdadeiras. Uma das críticas que se faz ao selecionismo é que a adaptação não garante a verdade. ${ }^{27}$ Além disso, nenhuma adaptação pode ser considerada absoluta em um processo evolutivo e, conseqüentemente, todo conhecimento passa a ser considerado falível.

\section{As epistemologias selecionistas de Popper e de Campbell}

K. Popper e D. Campbell, de forma independente e mais ou menos à mesma época, propuseram versões muito influentes de epistemologias selecionistas, com vários pontos em comum. Tais propostas servirão não somente para ilustrar os alvos e as características fundamentais das explicações selecionistas em epistemologia, mas também o(s) modo(s) como podem ser construídas e as hipóteses que pressupõem.

4-1. Popper: das metáforas ao paralelismo de processos seletivos

No livro A Lógica da pesquisa científica ${ }^{28}$ há algumas passagens nas quais Popper sugere uma analogia entre a maneira como teorias são testadas e a maneira como seres vivos competem e são selecionados de acordo com a sua adaptação diferencial ao meio ambiente. Essa analogia é motivada pelas críticas de Popper ao indutivismo, alicerçadas no pressuposto de que não há uma lógica da descoberta.

Nessas passagens, expressões emprestadas à teoria darwinista, como 'sobreviver', 'selecionar', luta pela sobrevivência', 'o mais adaptado', 'seleção natural', etc. são empregadas metaforicamente. Popper não sugere que exista qualquer identidade entre a natureza de teorias (ou a natureza do conhecimento) e a natureza dos seres vivos; ou identidade no nível dos processos específicos pelos quais ambos 'evoluem'. Ele não

27 Discuto a questão do realismo na conclusão do artigo. Ver, a esse respeito, Hull, 2001, p. 162; Downes, 2000. Cf. Papineau, 2003.

${ }^{28}$ A primeira edição deste livro, em alemão, data de 1934. A primeira edição inglesa é de 1959.

Revista de Filosofia, Curitiba, v. 16 n.18, p. 11-55, jan./jun. 2004. 
pretende resolver quaisquer problemas em epistemologia buscando similaridades estruturais com processos evolutivos em biologia. Seu objetivo tampouco é explicativo: as metáforas evolucionistas são usadas meramente para ilustrar a sua metodologia falsificacionista.

A epistemologia pressuposta por Popper nessa fase pode ser, portanto, entendida como 'evolutiva' em um sentido ainda metafórico. Para ele, as hipóteses e teorias científicas não são instruídas ou direcionadas pela experiência; em seus termos, elas não são geradas por um método indutivo, mas sim de forma cega, sendo posteriormente selecionadas por um meio ambiente empírico, por uma 'base empírica' composta por enunciados de observação. ${ }^{29}$

A situação muda a partir dos anos 60: Popper deixa para trás as inocentes metáforas evolucionistas do seu primeiro livro e aplica o selecionismo a processos ocomendo intemamente a um sistema cognitivo. Uma transferência crucial de conceitos tem agora lugar da epistemologia para a biologia: ele re-representa a evolução biológica à luz de conceitos epistemológicos. A partir daí, ele tenta abordar de modo unificado ambos os processos.

Popper deixa simplesmente de apontar vagas similaridades entre a dinâmica do conhecimento científico e a evolução das espécies, para defender uma continuidade entre esses processos, compromentendo-se com a tese de que a evolução dos seres vivos também pode ser vista como um processo de aquisição de conhecimento. Afirma-se, então, uma continuidade fundamental entre os diversos níveis: genético, fenotípico, comportamental e o do próprio desenvolvimento científico.

Popper espera, nessa fase, ser entendido literalmente quando afirma que o mecanismo de crescimento do conhecimento é o mesmo na ameba e em Einstein (!?):

Com este modo de apresentar a situação pretendo descrever como o conhecimento realmente cresce. Isso não deve ser entendido metaforicamente, embora faça uso, obviamente, de metáforas. A teoria do conhecimento que eu desejo propor é em grande medida uma teoria darwinista do crescimento do conhecimento. Da ameba até Einstein, 0 crescimento do conhecimento é sempre o mesmo: nós tentamos resolver os nossos problemas e obter, por um processo de eliminação, algo tendendo à adequação em nossas soluções tentativas (Popper, 1972, p. 261).

${ }^{29}$ Este meio ambiente é, portanto, simbólico, na medida em que está na esfera da linguagem e não dos fatos brutos, não expressos por meio de enunciados.

Revista de Filosofia, Curitiba, v. 16 n.18, p. 11-55, jan./jun. 2004. 
Não somente nós temos a mesma entidade - o conhecimento envolvida na dinâmica biológica e científica, mas também o mesmo 'método' de 'tentativa e eliminação do erro' controlando o seu 'crescimento' em ambos os contextos. Popper afirma que as 'tentativas' podem ser "novas reações, novas formas, novos órgãos, novos modos de comportamento, novas hipóteses" (Popper, 1972, p. 242; Hooker, 1995, p. 132).

Popper opõe, sistematicamente, a indução e a aprendizagem a partir da experiência - em termos do que estou chamando aqui de um processo instrucionista - à aprendizagem por tentativa e erro (numa perspectiva selecionista). ${ }^{30}$ A aprendizagem por tentativa e erro é associada ao modo como atua a seleção natural darwinista e à metodologia falsificacionista.

O antiindutivismo de Popper é formulado, nos seus últimos trabalhos, em termos do processo de variação cega: toda conjectura teórica é dita 'cega' porque o seu valor cognitivo não pode apoiar-se em um procedimento de indução a partir de uma base empírica. Uma conjectura teórica só pode ser avaliada com base nas suas conseqüências empíricas (deduzidas da mesma), podendo-se então aferir em que medida "se adaptam ao meio ambiente (simbólico)". Este meio ambiente pode incluir outras conjecturas teóricas bem como enunciados de observação. Trata-se, portanto, de um processo de variação cega, acompanhado de seleção.

Além de conceber a evolução como (um tipo de) crescimento do conhecimento, no seu artigo Of clouds and clocks (1965) Popper articula a hipótese de que os organismos são sistemas hierárquicos, compostos de diversos subsistemas que implementam os processos de variação cega e de seleção (ou de "controle plástico"):

Cada organismo pode ser visto como um sistema hierárquico de controles plásticos - como um sistema de nuvens controladas por nuvens. Os subsistemas controlados fazem movimentos de tentativa e erro que são parcialmente suprimidos e parcialmente restringidos pelo sistema controlador (Popper, 1972, p. 245).

Ainda nesse artigo, ele afirma que:

30 Popper não se utiliza dos termos 'instrucionismo' e 'selecionismo', como faço aqui. Mas ele tem claramente em vista as distinções entre diferentes tipos de processos de aprendizagem que distingui na seção 2.

Revista de Filosofia, Curitiba, v. 16 n.18, p. 11-55, jan./jun. 2004. 
...[A minha teoria] consiste numa certa visão da evolução como um sistema hierárquico crescente de controles plásticos, e de uma certa visão dos organismos como incorporando - ou no caso do homem, evoluindo de modo exosomático - este sistema hierárquico crescente de controles plásticos (1972, p. 242).

Na ciência, de forma análoga, as nossas teorias (conjecturas), diz Popper, "morrem em nosso lugar".

Entretanto, sabemos que, dada a sua metafísica de "três mundos”, Popper não pode chegar a uma descrição realmente unificada das dinâmicas biológica e epistemológica. Ele sustenta somente a existência de um paralelismo entre o que acontece no "terceiro mundo" (o epistemológico) e o que acontece nos outros dois "mundos" (o físico e o psicológico). Não existe qualquer teoria abstrata que possa ser igualmente instanciada em cada um desses mundos.

Em Popper, esse paralelismo está baseado em um "princípio de transferência” que Hooker formula da seguinte maneira: “... o que é verdadeiro logicamente no mundo $_{3}$ é verdadeiro causalmente no mundo ${ }_{1}$ e no mundo ${ }_{2}{ }^{31}$

O que Dennett $(1986,1995)$ chama de "criaturas popperianas" é um caso especial dos sistemas de controles plásticos de que fala Popper. Essas criaturas são capazes de armazenar informação do meio ambiente (físico e biológico). ${ }^{32}$ Essa informação é utilizada para pré-selecionar (controlar) as disposições comportamentais da criatura. A informação funciona, portanto, como um meio ambiente seletivo interno (ver fig. 3). Por serem capazes de pré-selecionar disposições para o comportamento que se mostram potencialmente danosas, as criaturas popperianas exibem um maior grau de adaptabilidade (ou "plasticidade", para usar o termo que prefere Popper) se comparadas às criaturas "darwinianas" e "skinnerianas".

31 Hooker In: Hahlweg \& Hooker, 1989, p. 104.

32 Essa informação pode, em certos tipos de sistemas, ter o caráter de uma representação do meio ambiente externo. Este meio ambiente, por outro lado, pode incluir não só objetos físicos, mas também outros sistemas cognitivos e seres vivos. Para uma epistemologia selecionista (ou evolutiva), constitui um objeto central de investigação saber como evoluíram sistemas capazes de armazenar informação a respeito do meio ambiente externo e diferentes modos de codificar essa informação e de utilizá-la no processamento cognitivo. Explicações para isso terão que ser propostas também em termos de processos seletivos. Ver também nota 39.

Revista de Filosofia, Curitiba, v. 16 n.18, p. 11-55, jan./jun. 2004. 
As criaturas skinnerianas, contrariamente às darwinianas, são capazes de condicionamento ${ }^{33}$, ou seja, de um tipo de aprendizagem através do qual modificam o seu comportamento de forma adaptativa durante a vida da criatura. ${ }^{34}$ Vimos que Skinner e Dennett consideram a "lei do efeito" em psicologia análoga ao princípio darwinista da seleção natural (ver fig. 2).

Seguem ilustrações de como funcionam, em termos de processos seletivos, as criaturas darwinianas, skinnerianas e popperianas: ${ }^{35}$

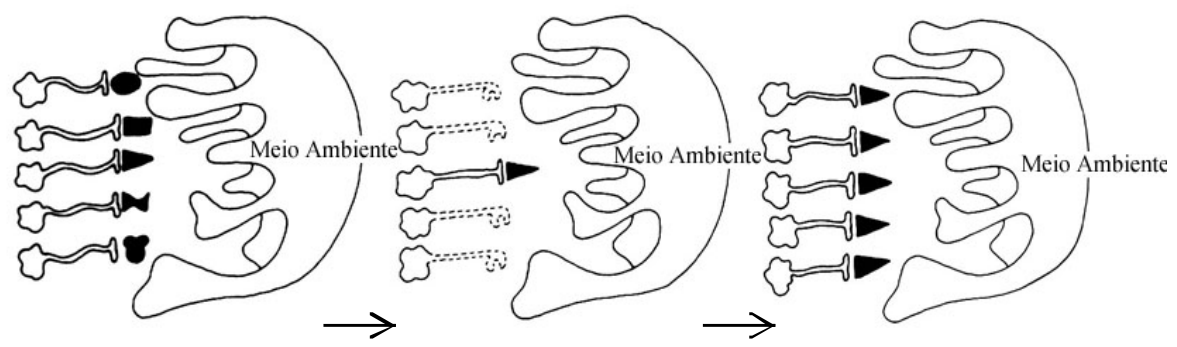

Fig 1: Criaturas darwinianas diferentes fenótipos 'rigidamente impressos' [hardwired] em sua constituição física
Seleção de um fenótipo, que é favorecido
Multiplicação do fenótipo favorecido

33 Vimos na seção 2 que o condicionamento pode ser pavloviano ou operante. A lei do efeito' é selecionista em seu caráter e só se aplica ao condicionamento operante. Portanto, as criaturas skinnerianas de que nos fala Dennett são capazes desse último tipo de condicionamento. Como todas essas criaturas operam segundo processos seletivos, Dennett não menciona criaturas, que poderíamos chamar de 'pavlovianas', que funcionariam segundo um processo instrucionista.

34 As criaturas darwinianas são aquelas que evoluem em conseqüência do processo seletivo darwinista, em um meio ambiente físico. Podemos, claro, também falar de 'aprendizagem', metaforicamente, ao longo da escala filogenética. Nesse caso, as criaturas darwinianas também 'aprendem' (não como indivíduos, mas como espécie). Em seguida, na reconstrução que propõe Dennett, surgiram criaturas com a capacidade de plasticidade fenotípica: nem todo processamento que ocorre nelas é 'rigidamente impresso' [hardwired], havendo margem para a aprendizagem e, conseqüentemente, para mudanças comportamentais ao longo da existência de cada criatura individual. Essas mudanças comportamentais podem ter implicações evolutivas na medida em que podem afetar o sucesso reprodutivo dos indivíduos dotados dessa capacidade (o chamado 'efeito Baldwin'). Esse efeito é estritamente darwinista, nada tendo de lamarckista. Ver Dennett, 1995.

${ }^{35}$ Adaptado de Dennett, 1995, p. 374-78.

Revista de Filosofia, Curitiba, v. 16 n.18, p. 11-55, jan./jun. 2004. 


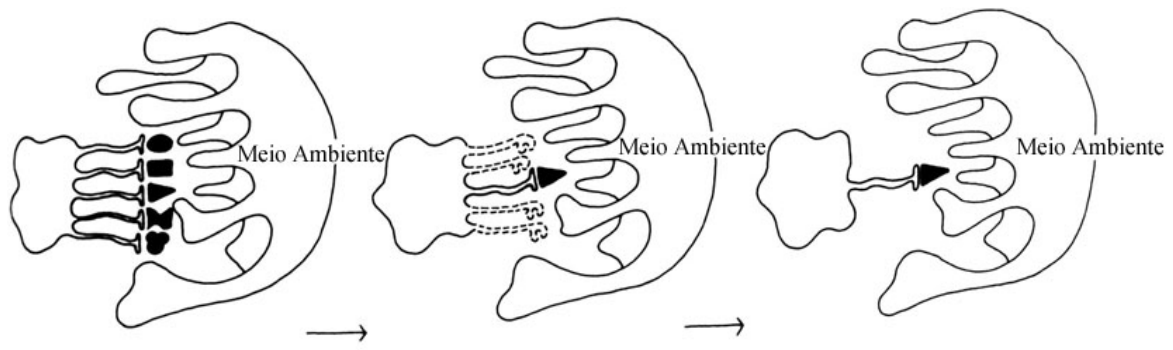

Fig 2: Criatura skinneriana tenta, de modo cego, diferentes respostas
... até que uma resposta é selecionada por 'reforço'
Da próxima vez, a primeira escolha da criatura será a resposta reforçada

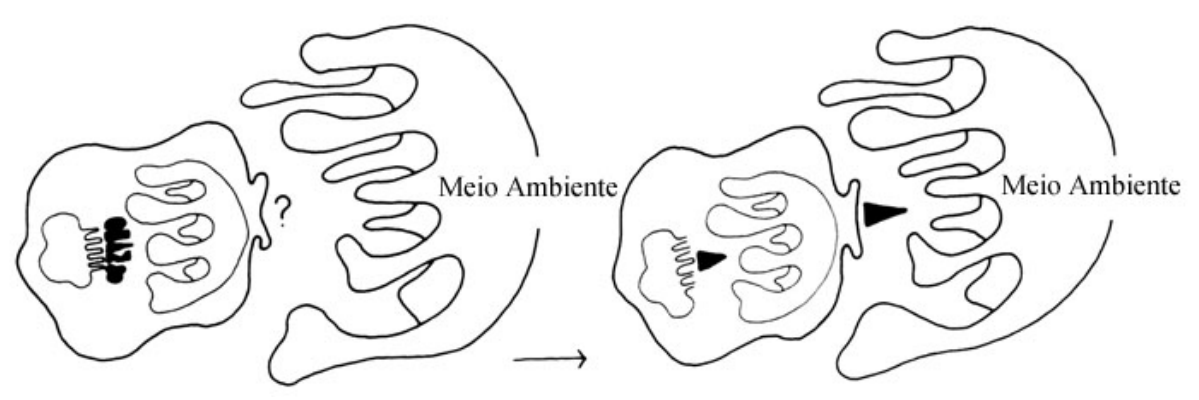

Fig 3: Criatura popperiana: possui um meio ambiente seletivo interno que préseleciona candidatos à ação

Já na primeira vez a criatura age de maneira previdente (melhor do que faria se se comportasse de modo aleatório)

Popper também antecipou o que Dennett chama de "criaturas gregorianas", que incorporam instrumentos (desenvolvidos por elas próprias) ao seu meio ambiente interno, com destaque para a linguagem (ver fig. 4) ${ }^{36}$ Desse modo, as criaturas gregorianas passam a ser capazes de manipular as suas representações do meio ambiente externo (e.g. fazendo simulações ou encadeando longos raciocínios). Assim, elas aumentam a sua adaptabilidade, relativamente aos outros tipos de criaturas anteriormente caracterizados. É razoável supor que nós, humanos, seja

36 Ver Popper, 1972, p. 329. Sobre a possibilidade de melhorarmos, desse modo, o nosso desempenho cognitivo e de sermos mais otimistas quanto a apostarmos na verdade como fim cognitivo, ver Papineau, 2003, p. 60. Ver também a discussão que faço a respeito do realismo epistemológico no final do artigo.

Revista de Filosofia, Curitiba, v. 16 n.18, p. 11-55, jan./jun. 2004. 
mos os únicos exemplos, atualmente existentes, de criaturas gregorianas. ${ }^{37}$

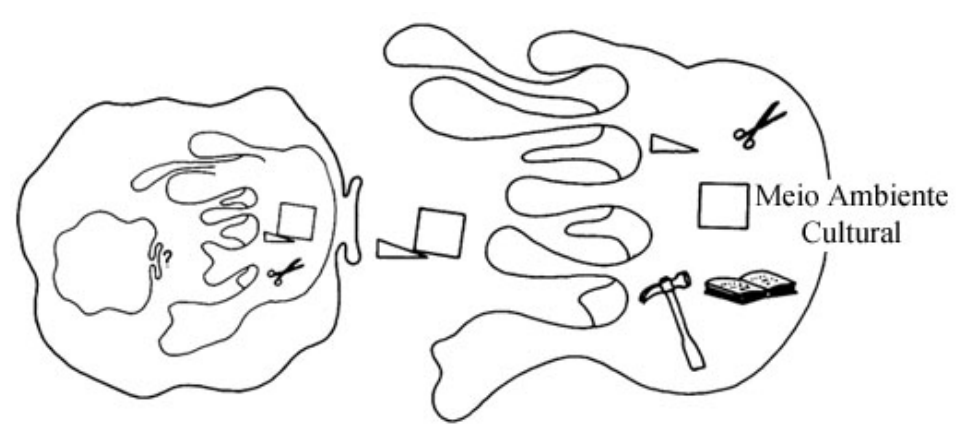

Fig 4: Criatura gregoriana assimilainstrumentos mentais do meioambiente (cultural); esses instrumentos melhoram tanto os seus geradores quanto os seus testadores.

Essas várias 'criaturas' que Dennett descreve, além de exemplicarem a atuação de processos seletivos em seu comportamento, estrutura e/ou funcionamento cognitivo, teriam por sua vez evoluído com base nesses mesmos processos. Dennett as ordena cronologicamente em uma "torre de gerar e testar": as criaturas darwinianas precederam as skinnerianas, estas as popperianas, e o surgimento das criaturas gregorianas é 0 mais recente na escala evolutiva. Em vez de "ganchos presos ao céu", como nas explicações providencialistas, temos ao longo desse processo a atuação de "guindastes" [cranes], processos que, supostamente, permitiram acelerar o processo de seleção natural mas que são, eles próprios, resultados do mesmo processo de seleção natural, desenrolando-se por vastos períodos de tempo.

${ }^{37}$ Com as criaturas gregorianas e o advento da linguagem criam-se, também, as condições para que ocorra uma evolução propriamente cultural, na qual tais criaturas tornam-se veículos de palavras e idéias (memes) que evoluem de forma autônoma (uma evolução exosomática, isto é, fora do corpo, tese já explícita em Popper; ver, acima, citação de trecho da p. 242 do seu artigo de 1972). Este é o objeto da 'memética' e também se relaciona, no caso de uma evolução do conhecimento científico, com 0 que Bradie chama de uma epistemologia evolutiva de teorias (ver seção 4-3). Levar também em consideração a hipótese de Dawkins de um 'fenótipo estendido', em que instrumentos, e, de modo geral, a cultura, as instituições, etc. podem ser vistos como extensões do nosso fenótipo biológico. Ver nota 50. 
4-2. Campbell: a internalização do processo seletivo

Campbell (1973) ampliou o "paradigma de uma hierarquia embricada de seleção e retenção" [nested hierarchy selective retention paradigm] aplicando-o a uma ampla gama de processos, indo dos níveis mais baixos - atômico, molecular e de formas primitivas de vida - até processos de alto nível em sistemas complexos. ${ }^{38}$

Ele extrapolou esse paradigma para "todos os processos de conhecimento": para as várias modalidades através das quais sistemas com diferentes graus de complexidade incorporam informação ("conhecimento") $)^{39}$ a respeito do meio ambiente.

Foi Campbell quem forjou a expressão "seletores vicários" [vicarious selectors], referindo-se à idéia, também presente em Popper, de

${ }^{38}$ Como assinalei, Campbell prefere usar a expressão 'epistemologia selecionista' para enfatizar que não está comprometido com uma analogia com o processo seletivo darwinista formulado em termos estritamente biológicos. Por esta razão prefiro usar, em vários pontos do texto, a expressão que favorece Campbell, em lugar da mais usual, 'epistemologia evolutiva', que aparece no título do artigo.

${ }^{39}$ É claramente problemático equacionar-se 'informação' e 'conhecimento'. Entre outras coisas, 'conhecimento' pressupõe consciência, já que envolve crenças e outros estados mentais de alto nível, sem falarmos na questão da justificação (que nos envolve com a discussão entre internalistas e externalistas; ver a esse respeito Abrantes \& Bensusan, 2003). Campbell (e acredito que muitos naturalistas) estão dispostos a falar de 'conhecimento' mesmo quando os estados ou processos envolvidos são inconscientes, automáticos, 'hardwired' (que poderíamos traduzir por 'impressos no circuito'). A esse respeito há um comentário interessante de Campbell relativo a um pressuposto, que eu qualificaria como ontológico, do programa selecionista:

“... Embora os processos de conhecimento conscientes do homem sejam reconhecidos como mais complexos e sutis que aqueles dos organismos inferiores, eles não são tomados como mais fundamentais ou primitivos. Nessa perspectiva, qualquer processo que forneça um programa armazenado para a adaptação dos organismos em ambientes externos é incluído como um processo de conhecimento, e qualquer ganho na adequação de tal programa é considerado um ganho em conhecimento. Se o leitor preferir, ele pode compreender esse artigo adequadamente tomando o termo 'conhecimento' como metafórico quando aplicado aos níveis inferiores da hierarquia de desenvolvimento. Mas como o problema do conhecimento - quando definido em termos de conteúdos conscientes do próprio filósofo - tem resistido a qualquer solução amplamente [generally] aceita, pouco parece se perder e, possivelmente, tem-se algum ganho ao se estender desse modo a gama [range] de processos considerados" (Campbell, apud Bradie, 2001, p. 40-1). Ver também Hull, 2001, p. 165; Papineau (2003, esp. a seção 10).

Revista de Filosofia, Curitiba, v. 16 n.18, p. 11-55, jan./jun. 2004. 
que a seleção de variações efetua-se nos diversos níveis, muitos deles internos ao sistema, nos quais a seleção - que seria de outro modo realizada pelo meio ambiente externo - é exercida 'por delegação' (substitutiva ou vicariamente) por alguma estrutura interna ao sistema. ${ }^{40}$ Alguma estrutura de controle, que tenha incorporado informação sobre o meio ambiente extemo (eventualmente na forma de uma representação ou modelo), substitui a ação seletiva direta deste ambiente e, assim, aumenta as chances de sobrevivência, a adaptabilidade do sistema. Evidentemente, o desenvolvimento dessas estruturas internas, com as funções especificadas, é também resultado de processos seletivos, ocorridos em etapas evolutivas anteriores (em uma escala filogenética), se não quisermos cometer petição de princípio. ${ }^{41}$

A hipótese de seletores vicários permite a Campbell conceber a modalidade humana de aquisição de conhecimento, e sua dinâmica, como estando em continuidade com modalidades epistêmicas/cognitivas anteriores na escala evolutiva:

Os processos humanos de conhecimento, quando examinados em continuidade com a seqüência evolutiva, resultam envolver mecanismos numerosos em vários níveis de funcionamento substitutivo, relacionados hierarquicamente, e com alguma forma de retenção seletiva em cada nível (Campbell, 1973, p. 419).

${ }^{40}$ Embora eu venha utilizando, de forma não ambígua, os termos 'interno' e 'externo' em que a fronteira corresponde aos limites do próprio sistema cognitivo -, com a noção de 'seletor vicário' essa fronteira desloca-se para dentro do sistema e surge, inclusive, a possibilidade de que existam várias dessas fronteiras (no caso de haver um empilhamento de seletores vicários). Esta é uma maneira de se entender a noção de 'seletor vicário': um meio ambiente interno incorpora informação a respeito do meio ambiente externo, como nas crituras popperianas (fig. 3). Os termos 'interno' e 'externo' passam a ser ambíguos e as fronteiras variam de sistema cognitivo para sistema cognitivo, ou mesmo dentro de um único sistema cognitivo. A tese da continuidade poderia ser colocada em termos de um deslocamento, ao longo da escala filogenética, da fronteira entre o que é interno e o que é externo, multiplicando-se 0 número de geradores e de testadores (meios ambientes seletores). Ver, também, Godfrey-Smith (1998).

${ }^{41}$ Campbell sugeriu que a adaptabilidade ao meio ambiente (a plasticidade de comportamentos) aumenta muitíssimo para sistemas estruturados 'em cascata' dessa maneira. $\mathrm{O}$ aumento da adaptabilidade via seleção externa é, de fato, muito mais lenta e arriscada do que via seleção interna. A aplicação desse "paradigma" a uma ampla gama de processos nos mais diversos níveis talvez motive o uso, por Downes (2000, p. 437-8), da expressão "abordagem de continuidade" para se referir a esta epistemologia selecionista (por oposição à abordagem de "paralelismo", adotada por Hull, entre outros).

Revista de Filosofia, Curitiba, v. 16 n.18, p. 11-55, jan./jun. 2004. 
Para Campbell e Popper, os órgãos dos sentidos ou, mais precisamente, as informações sensoriais que nos fornecem do meio ambiente, também funcionam como vicários, e não somente as representações de alto nível, simbólicas (Popper, 1972, p. 245).

Por exemplo, Campbell argumenta que a visão, ao fornecer informações que fazem o papel de um meio ambiente seletivo interno - que 'substitui' o meio ambiente físico extemo - serve para evitar uma exploração deste último por um arriscado contato direto do sistema com objetos do meio, através de uma locomoção feita às cegas (1973, p. 414-8). Os sistemas cognitivos dotados desse seletor vicário podem selecionar intemamente, previamente, dentre um conjunto de locomoções possíveis (geradas internamente por algum mecanismo de variação cega) o melhor deslocamento possível, dadas as circunstâncias. ${ }^{42} \mathrm{O}$ sistema cognitivo (digamos, um organismo) demonstra, em sua efetiva locomoção, possuir uma solução prévia do problema que lhe foi colocado (e.g. 'como chegar até ao alimento da forma a mais direta e rápida possível sem esbarrar em objetos potencialmente perigosos'). ${ }^{43}$ Em outras palavras, ele não se locomove às cegas. ${ }^{44}$ Essa

${ }^{42}$ Não é óbvia a comparação de criaturas dotadas de visão, que funciona como um seletor vicário, com as várias criaturas distinguidas por Dennett. Assinalo, simplesmente, que as representações das criaturas popperianas têm o caráter de representações simbólicas e não simplesmente de imagens, por exemplo, visuais.

${ }^{43}$ Campbell (1975) insiste que os órgãos de visão pressupõem uma associação, que é contingente, entre a opacidade dos objetos e a sua impenetrabilidade. A visão, para Campbell, evoluiu (como seletor vicário) em um meio ambiente particular, explorando de forma oportunista uma associação empírica freqüente entre penetrabilidade (dos objetos) e transparência. O conhecimento dessa associação, 'rigidamente impresso' [hardwired] nos órgãos visuais, é falível. Ou seja, a visão incorpora uma conjectura a respeito de como o mundo é, uma 'ontologia' se quiserem. Essa conjectura pode mostrar-se falha em ambientes distintos daqueles em que costumeiramente vivem os organismos dotados desse mecanismo vicário de seleção, ou em outros mundos possíveis. Quem já não presenciou pobres pássaros se estatelando ao tentarem voar através de nossas janelas de vidro? Isso pode ser generalizado, segundo Campbell: qualquer seletor vicánio incorpora conhecimento falível a respeito do mundo. Para uma epistemologia selecionista, aliás, todo conhecimento é falível, seja ele inato, seja adquirido durante a vida do indivíduo.

44 Notar que o termo 'cego' está sendo utilizado em diferentes contextos no parágrafo, nas expressões locomoção às cegas' e 'variação cega'! O processo seletivo envolve a geração às cegas de locomoções virtuais, emitidas por um gerador, e tais variações de deslocamentos virtuais são selecionadas por um meio ambiente vicário intemo, antes do sistema cognitivo exibir alguma efetiva locomoção (deslocamento físico). Como resultado, o deslocamento do sistema não é cego (aleatório) exibindo previdência (conhecimento presumido do meio ambiente físico/biológico) para quem observa, de fora, o seu comportamento.

Revista de Filosofia, Curitiba, v. 16 n.18, p. 11-55, jan./jun. 2004. 
pré-ciência, que nada mais é que informação incorporada pelo seletor vicário (no caso um órgão dos sentidos), deve ser explicada por processos seletivos ocorridos em uma escala filogenética. Dessa maneira, seletores vicários aumentam a adaptabilidade do organismo.

A aquisição de conhecimento teria, portanto, para Campbell, um caráter indireto e presumido [presumptive]: os seletores vicários presumem que o meio ambiente (externo) possui certas características. Se o meio ambiente modificou-se nesse ínterim, o seletor vicário pode não mais funcionar adequadamente. Há, portanto, uma historicidade e localidade inerentes ao funcionamento dos seletores vicários. ${ }^{45}$

Uma formulação abstrata do processo seletivo abre, portanto, as portas para se admitir que ele possa ocorrer 'em cascata' em um sistema complexo, que teria uma estrutura com diferentes níveis, em cada qual ocorrendo um processo de geração de variações e sua seleção. Nessa formulação, os processos seletivos são, por assim dizer, introjetados em um sistema individual, não se limitando às relações entre indivíduos, e destes com o meio ambiente externo ao sistema (como é o caso na biologia evolutiva).

Podemos ver esta como sendo uma hipótese a respeito de mecanismos cognitivos de tipo seletivo ocorrendo no indivíduo (Downes, 2000, p. 437-8). ${ }^{46}$ Outra maneira de vê-la é como uma estratégia metodológica para englobar a cognição individual. Na tentativa de responder pelos enigmas adaptativos propriamente cognitivos, a abordagem selecionista adota, em geral, essa estratégia de pressupor processos seletivos ${ }^{47}$ ocorrendo em diferentes níveis de um sistema complexo estruturado hierarquicamente.

45 Toda seleção é, portanto, local, ou melhor, oportunista. Nesse contexto, Kim leva a sério a noção de hierarquia: "... quando dois seletores vicários de diferentes níveis estão em conflito, nós nos ateríamos àquele mais geral, fundamental, mais antigo evolutivamente (àquele que está mais próximo do meio ambiente e que é, portanto, mais fundamental)" (Kim, 2001, p. 107).

46 Downes fala de um "modelo de continuidade ou de seleção embutida" (2000, p. 438).

47 Para simplificar, venho usando a expressão 'processo seletivo' em lugar de 'processos de variação, seleção e retenção'. É importante, contudo, ter sempre presente que 0 processo seletivo compreende distintos sub-processos. Ao utilizar 'processos seletivos' no plural, estarei referindo-me a diferentes ciclos de processos seletivos, ocorridos ao longo do tempo.

Revista de Filosofia, Curitiba, v. 16 n.18, p. 11-55, jan./jun. 2004. 
4-3. Duas espécies de epistemologias evolutivas?

M. Bradie $(1986,1995)$ propôs uma distinção entre dois programas em epistemologia evolutiva: EEM (uma epistemologia evolutiva de "mecanismos", ou melhor, dos aparelhos cognitivos ${ }^{48}$ ) e EET (uma epistemologia evolutiva de teorias).

A EEM enfoca os aparelhos cognitivos dos organismos (órgãos dos sentidos, cérebro, etc.) como produtos de um processo evolutivo que explicaria a sua evidenciada adaptação ao meio ambiente.

A EET, por outro lado, pretende simplesmente fazer uma extensão metafórica do processo evolutivo em biologia de modo a aplicá-lo diretamente à própria dinâmica do conhecimento (e não exclusivamente aos aparelhos cognitivos envolvidos na sua produção e dinâmica, objetos de uma EEM), incluindo aí o científico.49

É difícil, contudo, classificar epistemologias selecionistas como a de Campbell nessas categorias propostas por Bradie, na medida em que o "paradigma selecionista" daquele parece aplicar-se, literalmente, tanto à cognição individual quanto aos produtos das atividades cognitivas (e.g. teorias) e sua dinâmica. Campbell se compromete, como assinalei, com a tese da continuidade que, por sua vez, pressupõe a hipótese de seletores vicários. Como indiquei na nota 40, esta hipótese consiste, basicamente, em internalizar o processo seletivo, deslocando a fronteira entre o interno e o externo ou, se preferirem, a fronteira entre o elemento gerador de variações e o elemento que seleciona (o meio ambiente)..$^{50}$

${ }^{48}$ O termo 'mecanismo' é usado nesse contexto por Bradie no sentido de aparelho cognitivo (e.g. aparelho perceptual, estruturas cerebrais envolvidas na cognição, etc.).

49 Bradie percebe a EET como tendo um caráter metafórico e a EEM como uma aplicação literal do processo de seleção natural à epistemologia. A distinção entre duas espécies de epistemologia com base na dicotomia literal/metafórico é, a meu ver, discutível, e deve ser investigada de forma mais cuidadosa, como indico na última seção do artigo.

${ }^{50}$ Mesmo a epistemologia de Popper, a despeito do paralelismo que é obrigado a defender em função da sua metafísica de três mundos, dificilmente pode ser classificada nessas categorias propostas por Bradie (ver Downes, 2000, p. 440, n. 3). Podemos também tentar colocar a fronteira entre o interno e o externo fora do sistema cognitivo e ver 0 próprio desenvolvimento do conhecimento como envolvendo processos seletivos em diferentes níveis, para além do sistema individual. Por exemplo, a ciência pode ser vista como um sistema com diferentes partes (os cientistas) interagindo entre si segundo processos seletivos. Cada cientista, por sua vez, é também um sistema, com partes internas interagindo entre si segundo processos seletivos. Não desenvolverei aqui essas possibilidades de extensão do selecionismo.

Revista de Filosofia, Curitiba, v. 16 n.18, p. 11-55, jan./jun. 2004. 
Além disso, quando Popper e muitos outros sugerem que a evolução pode dar-se de modo exosomático (ver criaturas gregorianas, fig. 4), eles não pretendem ver esta evolução como sendo simplesmente uma extensão metafórica da evolução biológica, como avalia Bradie com a idéia de uma EET. ${ }^{51}$

\section{Críticas ao programa selecionista em epistemologia}

As críticas ao selecionismo são mais incisivas justamente no domínio da dinâmica cultural e, particularmente, da dinâmica (ontogenética) do conhecimento humano, que é o foco deste trabalho.

A objeção mais comprometedora à extensão do programa selecionista de forma a abarcar a epistemologia aponta para o contraste entre o caráter cego [blind] da geração de variações no caso da evolução orgânica, e o caráter intencional da geração do conhecimento, em especial na atividade científica. ${ }^{52}$ Essa geração é, afirmam os críticos, baseada em um conhecimento prévio acumulado; o cientista adota, além disso, métodos e tem em vista a resolução de problemas particulares.

No caso da geração de variações conceituais, o qualificativo 'cego' refere-se à característica de que, na geração de novas variações, o sistema cognitivo - no caso da ciência, o cientista - não antevê ou possui previdência de que tais variações vão ser soluções para os problemas que ele se coloca (ou que o meio ambiente coloca ao sistema).

Bradie, em artigo recente, reproduz as três conotações do termo 'cego' em um contexto epistemológico, apontadas por Campbell:

"(1) As respostas não são acopladas às condições ambientais, que não ocasionam a emissão das primeiras; (2) As respostas tentativas individuais não estão correlacionadas com a solução; [...] (3) Respostas sucessivas não são correções de respostas prévias" (Bradie, 2001, p. 41; cf. Campbell, 1973, p. 422).

Para Kim, dizer que as variações conceituais são 'cegas' significa afirmar que as diversas alternativas geradas (tentativas experimentais,

51 Na conclusão indico uma investigação, em curso, sobre esta questão, que envolve a dicotomia literal/metafórico e também a estrutura do raciocínio analógico.

52 Embora as críticas que aqui apresento são focadas no conhecimento científico, elas podem ser também colocadas, em termos similares, para o conhecimento em geral.

Revista de Filosofia, Curitiba, v. 16 n.18, p. 11-55, jan./jun. 2004. 
hipóteses, teorias, etc.) não são umas "mais prováveis de serem corretas do que outras" (Kim, 2001, p. 109).

Mesmo Toulmin, que propôs uma versão de epistemologia evolutiva (selecionista), admite a falha na analogia. Há dois modos como podem dar-se as relações entre variação e seleção: elas podem ser casadas (acopladas) ou descasadas (desacopladas). Embora os processos de evolução biológica e de evolução científica exemplifiquem um mesmo "padrão formal de explicação populacional" - afirma Toulmin - existe, porém, uma dissimilaridade fundamental entre a mudança conceitual e a especiação orgânica: no desenvolvimento das disciplinas científicas, contrariamente à evolução orgânica, há um 'casamento'/ 'acoplamento' [coupling] entre a produção de variações conceituais/teóricas e a seleção intelectual dessas variações (1972, p.338).

Toulmin ressalta que o darwinismo, ao defender que o processo de variação é cego, rejeita a ortogênese, ou seja, a tese de que as mutações dar-se-iam em direções que garantem a adaptação. A evolução científica, contudo, seria de um outro tipo, no qual a geração de variações conceituais não seria cega, mas sim direcionada por métodos (que são cristalizações de conhecimento acumulado) e restringida pela necessidade de resolver determinados problemas. Richards (1981, p. 56) sublinha que Toulmin esposa, portanto, um lamarckismo no que diz respeito à evolução do conhecimento, e não um genuíno selecionismo.

Essa crítica, feita por Toulmin, é também claramente enunciada por Thagard, após apresentar as características da variação cega na evolução orgânica, características essas que distingui acima:

"Quando os cientistas chegam a novas idéias, eles usualmente o fazem como resultado de uma preocupação com problemas específicos. Portanto, contrariamente à variação biológica, a variação conceitual é dependente das condições ambientais" (Thagard, 1988, p. 103; 107)..$^{53}$

53 O meio ambiente, no caso, seria um conjunto de problemas e não, diretamente, 0 mundo físico. Usando uma distinção de tipos de problemas científicos feita por Laudan, é claro que os "problemas empíricos" são, no caso da ciência, centrais; mas não se pode, com isso, diminuir a importância dos "problemas conceituais" nessa atividade. Thagard está afirmando que, em ciência, a geração de variações é acoplada a tal meio ambiente composto por problemas científicos. Thagard traduz essa analogia negativa (ou seja, essa falha na analogia) como um acoplamento, na atividade científica, entre o contexto de descoberta e o de justificação (1998, p. 106).

Revista de Filosofia, Curitiba, v. 16 n.18, p. 11-55, jan./jun. 2004. 
Em ciência - segue a objeção à pertinência de uma epistemologia selecionista (evolutiva) - as teorias não são geradas cegamente, mas tendo-se em vista determinados fins e adotando-se procedimentos heurísticos - baseados no conhecimento previamente acumulado - que limitam as alternativas teóricas consideradas plausíveis.

Mesmo filósofos da biologia favoráveis a dar ao darwinismo uma maior abrangência, aplicando-o a diversas áreas da filosofia, como é o caso de M. Ruse, apontam para essa falha na analogia. Para Ruse, “... as desanalogias são tão grandes que provavelmente qualquer tentativa de ver a mudança na teoria científica através das lentes do evolucionismo Darwinista causa mais prejuízos que benefícios. Eu não tenho visto nenhuma razão para mudar essa opinião”.

Ruse aponta, especificamente, para a falha na analogia relativa ao modo como são geradas as idéias científicas:

“... a maior parte de novas idéias surge somente como resultado de um grande esforço dirigido, e elas são por sua vez dirigidas, ou projetadas para a tarefa em vista” (Ruse apud Kim, 2001, p.109).

Esses trechos são extraídos de um artigo ${ }^{54}$ de Ruse datado de 1983. Em um livro mais recente, embora se proponha a "levar Darwin a sério", a mesma crítica reaparece:

As variações científicas são dirigidas, as orgânicas não. Mas o que significa essa diferença? Significa que Nicolau Copérnico, ou Charles Darwin, ou James Watson tinham um objetivo em mente - a compreensão da Natureza - que dirigiu e regulou a ciência que eles produziram. Em outras palavras, o cientista tinha um papel ativo no curso da ciência (Ruse, 1995, p. 93).

Ruse acusa os selecionistas, em particular, de não distinguirem entre "algo 'ser desconhecido' e algo 'ser aleatório' ".

Cassini, na mesma linha, menciona o argumento de Peirce de que seria altamente improvável fazer-se qualquer avanço em ciência se a geração de hipóteses ou teorias fosse feita ao acaso (Cassini, 1998, p. 26).

Thagard vê, também, uma relação entre a taxa de produção de variações teóricas e a situação de estabilidade ou de crise em que se

${ }^{54}$ Ruse, Darwin and philosophy today. In: Oldroyd \& Langham (eds.) The wider domain of evolutionary thought. Dordrecht: Reidel, 1983, p. 133-168. 
encontra uma disciplina científica - sendo essa taxa maior em situações de crise (um dos traços que Kuhn atribui aos períodos de ciência extraordinária). Na evolução orgânica, ao contrário, o meio ambiente não exerce nenhuma influência sobre essa taxa (Thagard, 1988, p. 107).

\section{5-1. Respostas dos selecionistas às críticas}

Os epistemólogos selecionistas não estão, em geral, dispostos a considerar o caráter dirigido, teleonômico, das variações conceituais em ciência como uma falha na analogia. Eles julgam essencial que as variações sejam cegas em qualquer processo seletivo, incluindo a evolução do conhecimento científico (ou, de modo mais amplo, a evolução da cultura). Acatar tal crítica (de falha na analogia) faria perder força heurística e/ou explicativa à tentativa de ver a evolução do conhecimento científico como um genuíno processo seletivo. ${ }^{55}$

Campbell e Popper, que poderíamos considerar os pais da epistemologia selecionista contemporânea, foram, de fato, enfáticos em considerar a geração de teorias científicas como um processo de variação cega, à semelhança da evolução orgânica: "Eu vejo essa idéia de 'cegueira' [blindness] de tentativas em um movimento de tentativa-e-erro como um passo importante, indo além da idéia errônea de tentativas aleatórias" (Popper apud Kim, 2001, p. 103).

Epistemologias selecionistas, como a de Campbell, assimilam essa aparente falha na analogia considerando que, de fato, existem restrições à variação conceitual, teórica, no caso da ciência; mas que restrições análogas também atuam na evolução orgânica, na medida em que a evolução atua sobre pré-adaptações, ou seja, a partir de estruturas orgânicas preexistentes, que a 'canalizam'. O análogo das características genéticas, anatômicas, etc. que restringem a geração de variações nos organismos vivos seria, em ciência, o conhecimento já disponível que restringe, de diversos modos, a geração de novas variações teóricas e experimentais.

Kim responde, nessa mesma linha, às críticas de Ruse que, como

55 Ver Munz,1993; Kantorovich,1993, p. 146, 148 et seq.

Revista de Filosofia, Curitiba, v. 16 n.18, p. 11-55, jan./jun. 2004. 
... A preocupação de Ruse com a refutação da analogia entre as variações orgânica e científica o leva a negligenciar as restrições [constraints] existentes (genéticas, anatômicas, etc.) que afetam a gama de variações que são possíveis. Assim, ele argúi como se a variação biológica fosse completamente aleatória, no sentido de que qualquer coisa pode emergir das características da espécie. Do mesmo modo que a geração, bem como a seleção, dos pensamentos-tentativos [thought trials] são restringidas pelas explorações vicárias em um meio ambiente vicário [incorporado] no pensamento, o pano de fundo genético e as peculiaridades da espécie em questão restringem e, nesse sentido, pré-selecionam a gama de possíveis variações (Kim, 2001, p.111).

Os selecionistas distinguem, de fato, variações aleatórias [haphazard or random] de variações cegas. Cziko, por exemplo, esclarece que o emprego do qualificativo 'cego', no contexto do selecionismo, não significa que as variações não sejam restringidas. Se fosse esse o caso, o termo adequado seria 'aleatório', ou seja, todas as variações seriam igualmente prováveis. Em ciência, as variações são certamente restringidas pela experiência e pelo conhecimento previamente adquiridos, mas, em última análise, não deixa de existir uma componente cega na investigação.

Cziko assinala que se não estamos dispostos a "retornar a explicações providencialistas e instrucionistas", as restrições à variação, no caso da ciência, como de resto em biologia, "devem ser vistas como enigmas adicionais de adaptação" e, portanto, explicadas em termos de processos seletivos ocorridos no passado filogenético (Cziko, ibid., cap. 15, p. 7).

Trata-se de rejeitar a visão tradicional, segundo a qual os resultados científicos possuem um "caráter teleológico" e substituí-la por "uma explicação mecanística das adaptações maravilhosas das variações conceituais aos problemas científicos" (Kim, 2001, p. 103). ${ }^{56}$ Articular uma explicação mecanística para a criatividade seria, nesse sentido, uma das motivações para a adoção do selecionismo em epistemologia.

A diversidade de casos de enigmas de adaptação exige, entretanto, que se perceba a "complementaridade entre diferentes tipos de variação cega e retenção seletiva” - título de um artigo recente de Cziko

56 Como em outras passagens dessa discussão, faço notar que o meio ambiente aqui é constituído por um conjunto de problemas.

Revista de Filosofia, Curitiba, v. 16 n.18, p. 11-55, jan./jun. 2004. 
(2001). Vimos, anteriormente, que o processo seletivo pode dar-se entre sistemas (indivíduos em uma população) ou no interior de um sistema particular. Também é preciso distinguir os efeitos de processos seletivos ocorridos no passado (antecedentemente) - seja no passado filogenético seja ontogenético - dos que ocorrem no presente. Campbell já fizera tais distinções em seu artigo de 1973, que discute diferentes casos e níveis de resolução de problemas, indo daqueles enfrentados por organismos com uma estrutura rudimentar, até os complexos procedimentos de resolução de problemas em ciência, que envolvem criatividade.

Para o conhecimento inato que se expressa em hábitos e comportamentos instintivos nos animais, por exemplo, o selecionismo apela somente para processos seletivos que ocorreram entre indivíduos de uma população, ao longo da sua história filogenética.

Já para o conhecimento aprendido ao longo da história ontogenética de um indivíduo, embora processos seletivos que se deram na história filogenética sejam sem dúvida relevantes - por exemplo, para explicar a adaptação de órgãos de percepção ou do cérebro, certamente envolvidos na cognição e, portanto, na aquisição de conhecimento - 0 selecionismo apela para uma participação crescente de processos seletivos ocorrendo internamente ao indivíduo no presente, ou que tenham ocorrido no seu passado ontogenético (resultando em aprendizagem). ${ }^{57}$ Processos seletivos que ocorreram no passado respondem, por exemplo, pelo fato de que um conhecimento já adquirido pode restringir a aquisição de novos conhecimentos, por meio de métodos e heurísticas.

No caso de um conhecimento (ou comportamento) totalmente novo - ou seja, pouco ou em nada similar a conhecimentos já adquiridos e que, portanto, pressupõem criatividade - processos seletivos ocorrendo internamente ao indivíduo e no presente, com pouca ou nenhuma restrição por parte de processos seletivos ocorridos no passado têm, proporcionalmente, maior participação.

Kim defende o mesmo ponto:

57 Convém aqui distinguir os processos seletivos envolvidos, por exemplo, na embriogênese (e.g. no desenvolvimento do cérebro dos animais) e, de modo mais geral, no desenvolvimento de um indivíduo, de um lado, dos processos seletivos envolvidos na aprendizagem propriamente dita, de outro (e.g. condicionamento operante, aprendizagem da linguagem, incorporação de elementos culturais, etc.). Ambos os processos poderiam ser classificados sob a rubrica de 'ontogênese' - já que ocorrem durante a vida de um indivíduo - para distingui-los, em bloco, dos processos evolutivos ocorridos na 'filogênese'.

Revista de Filosofia, Curitiba, v. 16 n.18, p. 11-55, jan./jun. 2004. 
Quando instado a dar uma solução para um problema intelectual particular, um cientista gera um certo número de pensamentos-tentativos bem como experimentos-tentativos para encontrar uma solução para aquele problema. Ao fazer isso, ele ou ela podem reduzir o espaço de busca servindo-se de resultados prévios de pesquisa, que são baseados nos modelos, teorias e instrumentos de registro [inscription devices] disponíveis à época. Entretanto, para além desses processos restringidos, ele ou ela tem que buscar cegamente a solução para o novo problema (Kim, 2001, p.108).

Esse tipo de complementaridade entre processos seletivos que ocorreram no passado - filogenético e ontogenético - e processos seletivos que ocorrem no presente, não parece, entretanto, aceitável para muitos. ${ }^{58}$

Os defensores do selecionismo não negam que o cientista, ao gerar variações teóricas e hipóteses, tem em vista a solução de determinados problemas, além de ser guiado por um conhecimento previamente acumulado (freqüentemente cristalizado em métodos ou heurísticas adotadas conscientemente). Eles simplesmente enfatizam que esse conhecimento prévio precisa, ele próprio, ser explicado com base em processos seletivos ocorridos no passado (filogenético ou ontogenético), se não se quiser cometer petição de princípio na explicação de adaptações (no caso conceituais, teóricas).

Cziko, por exemplo, sentencia que Thagard, ao dizer que as variações estão,

... 'correlacionadas com as soluções de problemas' comete petição de princípio com respeito a como esse conhecimento prévio que guia [o cientista] foi obtido em primeiro lugar. Nossa cientista, diferentemente do processo de evolução orgânica, quase certamente possui um fim e ela gera as variações metodológicas e teóricas em uma tentativa de atingir esse fim. Mas na medida em que novas descobertas são feitas para as quais não existe conhecimento prévio, esse crescimento do conhecimento científico e tecnológico é possível somente pela produção e teste de novas variações experimentais cujos resultados são desconhecidos até serem testados. Como colocou Campbell, o segredo da inovação racional é a seleção retrospectiva [hindsighted] e não a variação previdente [foresighted] (Cziko, 1995, cap. 15, p. 6; cap. 9, p. 3).

58 Ver, por exemplo, Cassini, 1998, p. 28-9.

Revista de Filosofia, Curitiba, v. 16 n.18, p. 11-55, jan./jun. 2004. 
Sem falar no caráter necessariamente falível de qualquer variação (teórica, metodológica, tecnológica, etc.) que, como disse anteriormente, é uma implicação de uma epistemologia selecionista.

Enfatizo, uma vez mais, que o selecionismo envolve o misto de um elemento de variação cega - eventualmente com restrições possibilitadas

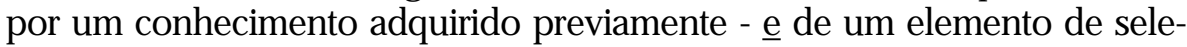
ção (em nada cego). ${ }^{59}$ Ambos os subprocessos são imprescindíveis para explicarmos adaptações.

Cziko defende que

... do mesmo modo que a evolução biológica depende da existência de variação cega na estrutura e no comportamento dos organismos, a ciência depende de uma variação cega similar nas hipóteses que são propostas. Isso não significa que as hipóteses não são restringidas pelo conhecimento já obtido (...) Tanto na evolução biológica quanto na ciência, tais restrições refletem a acumulação passada do conhecimento por uma prévia variação cega e seleção, que são essenciais para limitar os tipos futuros de variação que aparecem. Mas as restrições, por si só, não podem responder pela emergência de novas e melhores adaptações do organismo ao meio ambiente, e da teoria científica ao universo (Cziko, ibid. cap. 10, p. 13). ${ }^{60}$

Kantorovich faz uma tentativa de responder à objeção de que a descoberta científica não é (aparentemente) cega supondo estágios subconscientes de variação cega e de seleção de idéias nos processos cognitivos dos cientistas. ${ }^{61}$ Do mesmo modo como são geradas novas variações nos seres vivos, a geração de novas conjecturas na ciência seria também, em última instância, cega, isto é, não “... influenciada pela 'pressão' dos problemas que elas devem resolver ou dos dados que elas supostamente devem explicar" (1993, p. 146).

Uma crítica análoga aponta para o desperdício que estaria necessariamente associado a um genuíno processo de variação cega, já que muitas das variações (idéias, teorias, hipóteses) seriam inadequadas, erros simplesmente (do mesmo modo que a maior parte das variações no domínio biológico). ${ }^{62}$

${ }^{59}$ Ver, a esse respeito, Calvin (1990).

${ }^{60}$ Há diferente tipos de meios ambientes seletivos nesse parágrafo, gerando bastante ambigüidade, um traço a meu ver problemático do programa selecionista. Voltarei a discutir esse ponto na seção final.

${ }^{61}$ Pode-se ver esta hipótese de Kantorovich como uma previsão de sua epistemologia que necessitaria, evidentemente, de corroboração. A mesma exigência pode ser feita com respeito à hipótese de Campbell de seletores vicários, algo que discuto na seção final do artigo.

${ }^{62}$ Ver, a esse respeito, o argumento de Peirce, a que fiz referência no início do artigo.

Revista de Filosofia, Curitiba, v. 16 n.18, p. 11-55, jan./jun. 2004. 
Cziko retruca que “... esse desperdício pode ser compreendido como um preço inevitável que deve ser pago por um processo no qual novas adaptações e conhecimento podem emergir sem intuições [insights] providencialistas externas e miraculosas, ou sem um guia instrucionista miraculoso" (1995, cap. 15, p. 5).

Cziko chama a atenção, além disso, para um fato inegável: 0 grande número de fracassos que ocorrem tanto no trabalho científico quanto no tecnológico. Sabemos que os erros dos cientistas são, em geral, escamoteados por uma historiografia da ciência presentista que só registra o que é considerado acerto do ponto de vista do estágio atual do conhecimento. ${ }^{63}$ Tal historiografia, diz Cziko, tende a reforçar a visão de que a atividade científica é 'dirigida', envolve previdência, instrução, e não um processo "doloroso" de tentativa e erro (Ibid, cap. 15, p. 5).

A controvérsia que desenvolvi nesta seção refere-se à existência ou não de falhas relevantes no tocante ao subprocesso de variação (como parte do processo seletivo), comparando como este se dá em biologia e em epistemologia. Há também críticas que apontam para falhas na analogia quanto aos outros dois subprocessos darwinistas: os de seleção e de retenção de características. ${ }^{64}$

\section{Variações finais em torno do tema}

O meu principal objetivo neste artigo foi o de apresentar a epistemologia evolutiva (ou selecionista) como tendo, fundamentalmente, as mesmas motivações do darwinismo em biologia. Tanto a rápida passagem que fiz pela psicologia, quanto a exposição detalhada das respostas dos epistemólogos evolutivos a vánias críticas que receberam, foram meios de explicitar essas motivações do selecionismo: a motivação naturalista, a mecanicista e a de rejeitar petição de princípio em explicações para adaptações de modo geral.

É claro que um programa dessa natureza não se justifica unicamente por suas motivações, mas, sobretudo, por seus resultados. Ao

63 Para uma caracterização do tipo presentista de historiografia da ciência, ver Abrantes, 2002.

${ }^{64}$ De modo a manter a extensão esse artigo dentro de limites razoáveis, não analisarei essas outras críticas, muito menos contundentes do que as aqui apresentadas.

Revista de Filosofia, Curitiba, v. 16 n.18, p. 11-55, jan./jun. 2004. 
levarem adiante esse programa selecionista em epistemologia, os seus articuladores pretendem não só recusar determinadas abordagens que consideram inaceitáveis - pelas razões que expus detalhadamente - mas também resolver, ou talvez desfazer, alguns dos problemas que têm se mostrado renitentes desde que essa área deu os primeiros e firmes passos com Platão.

Aqueles que não são simpáticos às motivações desse programa, ou que as consideram descabidas, evidentemente tenderão a recusá-lo em bloco e de antemão, sem examinar as suas implicações. Nesse grupo estarão, certamente, os que rejeitam completamente o darwinismo mesmo em biologia (quanto mais em epistemologia!), e possivelmente também aqueles que são críticos de somente alguns aspectos do mesmo (por exemplo, os críticos de um adaptacionismo exacerbado). Também encontraremos nesse grupo, filósofos alérgicos a qualquer proposta naturalista, vendo-as como ameaças à própria autonomia da filosofia.

Espero que mesmo esses críticos radicais, se chegaram até aqui, tenham tirado proveito da leitura do artigo, não só por encontrarem explicitadas o que me parecem ser as motivações do programa, mas sobretudo por verem exploradas algumas das suas implicações, que poderão fornecer munição adicional às suas críticas e, provavelmente, consolidar a sua antipatia!

No estágio atual de desenvolvimento do programa, algumas das suas deficiências e limitações são bastante evidentes.

Na frente explicativa do programa, alguns críticos apontam para a ausência de evidência empírica cabal a favor de algumas hipóteses que os selecionistas propõem - como a de seletores vicários - que lhes permitem articular explicações para adaptações epistemológicas. ${ }^{65}$ Tais hipóteses são falseáveis? Em caso afirmativo, que evidências haveria a favor (ou contra) a existência de estruturas (neurofisiológicas?) que implementariam a internalização dos processos de geração e de retenção seletiva em diferentes sistemas cognitivos? Se muitos filósofos estão dispostos a ignorar tal tipo de crítica, por acharem que teorias filosóficas são indiferentes à evidência empínica, esse certamente não é o caso dos naturalistas.

Na frente ontológica do programa, filósofos poderão dizer que

${ }^{65}$ Ver, por exemplo, Bradie, 2001, p. 42.

Revista de Filosofia, Curitiba, v. 16 n.18, p. 11-55, jan./jun. 2004. 
naturais, como a biologia) - um dos projetos dos naturalistas ${ }^{66}$ - ainda são incipientes e enfrentam graves dificuldades, apesar de passos significativos já terem sido dados nessa direção. ${ }^{67}$ Em que medida 0 conhecimento e os processos que o geram podem ser considerados fenômenos naturais?68 Os epistemólogos devem encarar os seus problemas como adaptativos, conseqüentemente tendo que responder a questões relativas a funções, projetos, etc. e a como surgiram? É certo que sempre encontraremos alguém pronto para brandir a tradicional acusação de que se está incorrendo na famigerada falácia naturalista...

Há também dificuldades em se tratar de processos que parecem intrinsecamente intencionais - como os cognitivos e os de geração de conhecimento, justamente os que importam para a epistemologia - adotando-se uma postura mecanística estrita em que se recusa toda teleologia, a despeito dessa postura, em biologia, ter obtido um indiscutível sucesso. Uma análise do conceito de função pode ser central em ambas as áreas. Vimos que mesmo filósofos como Toulmin e Ruse, simpáticos de modo geral ao selecionismo, apontam para o caráter dirigido, intencional, da geração de variações (teorias, metodologias, etc.) em empreendimentos cognitivos como as ciências. Se há seleção aqui, ela se parece mais com uma seleção artificial do que com uma seleção natural. Os selecionistas tentam, claro, introduzir seletores vicários, 'guindastes' no sentido de Dennett, que explicariam o finalismo (aparente) desses processos em termos de outros processos, ocorridos antecedentemente e, em última instância, mecanísticos. Os valores e os fins da comunidade científica poderiam ter, por exemplo, o caráter de um meio ambiente seletivo vicário, a ser explicado por processos seletivos e, portanto, mecanísticos.

Algumas implicações de uma abordagem selecionista em epistemologia podem ferir outras intuições bastante arraigadas. Por exemplo, alguns considerarão inaceitáveis implicações que parecem incontornáveis de uma abordagem selecionista em epistemologia, como o fali-

66 Em Goldman, 1998 temos uma esclarecedora tentativa de distinguir as várias vertentes do naturalismo em epistemologia.

67 Ver, por exemplo, Millikan, 1984.

68 Para uma incisiva defesa da tese de que o conhecimento deve ser visto como um fenômeno natural, inclusive não restrito a humanos, configurando um 'tipo natural' [natural kind], ver Kornblith (2002, esp. cap. 2).

Revista de Filosofia, Curitiba, v. 16 n.18, p. 11-55, jan./jun. 2004. 
bilismo. Os realistas epistemológicos também não verão com bons olhos que o caráter necessariamente local de toda adaptação parece implicar uma posição não-realista, já que a verdade possui um caráter global. Em outras palavras, se há evolução das nossas crenças, isso não pode ser visto como uma aproximação da verdade. ${ }^{69}$ No entanto, o progresso, embora não faça sentido no contexto da evolução biológica, parece-nos um traço característico da dinâmica do conhecimento científico (ao menos). ${ }^{70}$

É evidente que se as implicações de um programa ferem intuições que nos são caras, isso pode ser considerado uma razão para rejeitá-lo (sobretudo por filósofos, que tanto se ancoram nelas). Mas isso pode também ser encarado como um preço a pagar por progressos em nossa compreensão do mundo e de nós mesmos. Alguns dos grandes avanços realizados tanto em filosofia quanto em ciência solaparam intuições arraigadas. A mecânica quântica é um exemplo eloqüente disso. A própria teoria de Darwin abalou profundamente as nossas intuições a respeito de como nos inserimos na natureza, por mais claras e distintas que tenham parecido ao longo de séculos, para não dizer milênios.

Mesmo aqueles que, como eu, são simpáticos às motivações do programa selecionista em epistemologia terão críticas, ou pelo menos dúvidas, por exemplo, no que diz respeito à sua abrangência, que por vezes parece-me excessiva. A que preço buscamos estender esse programa a outras áreas, mesmo que estejamos bem motivados?

Incomoda-me, por exemplo, a facilidade com que os selecionistas redefinem o que seja o meio ambiente seletivo, e também sua ambigüidade na caracterização das variações relevantes, em tentativas de se aplicar o processo seletivo à temática epistemológica (e, de um modo geral, à evolução cultural). Sublinhei, em vários momentos ao longo do texto, como os epistemólogos selecionistas são pródigos em conceber os mais diversos tipos de meios ambientes além do físico (que

69 Ver Bechtel, 1990. O realismo epistemológico não deve, contudo, ser confundido com o realismo metafísico. Os selecionistas são, inequivocamente, realistas no último sentido: eles pressupõem que existe uma realidade, um mundo extramental autônomo; mais do que isso, eles defendem que mentes, na verdade, são produtos de processos naturais ocorridos nesse mundo (Wuketits, 1984, 2001). Os selecionistas, portanto, parecem comprometidos, ao mesmo tempo, com um não-realismo epistemológico e com um realismo metafísico (Stein, 1990)! Haverá, certamente, filósofos que torcerão o nariz para um tal híbrido (embora não haja, necessariamente, inconsistência nele).

70 Ver Ruse, 1990; Stein, 1990.

Revista de Filosofia, Curitiba, v. 16 n.18, p. 11-55, jan./jun. 2004. 
é o meio ambiente padrão em explicações para adaptações): um meio ambiente de problemas; de valores; de conceitos e de teorias; de dados empíricos, sensoriais, e por aí vai. Como esses diferentes meios ambientes se relacionam e que papéis desempenham em explicações particulares? De toda forma, não deixo de perceber nessa proliferação um certo artificialismo, tentativas ad hoc de articular o que alguns vislumbram como um "darwinismo universal", com ramificações nas mais diversas áreas. De modo geral, acho bastante suspeitas propostas de 'teorias de tudo', tentativas por demais extremadas de unificação explicativa.

Quero também deixar em aberto outras questões - algumas delas explicitamente colocadas ao longo do artigo - que espero possam motivar novas investigações no âmbito desse programa.

Um elenco de questões tem um caráter metodológico. Qual o papel que analogias desempenham na formulação de uma epistemologia evolutiva (ou de qualquer teoria que tenha um caráter selecionista)? Nesse contexto, faz mesmo sentido a distinção, que propôs Bradie, entre uma epistemologia evolutiva metafórica (ou analógica) e uma epistemologia evolutiva literal?

Como se obtêm abstrações de tipos explicativos tomando-se como ponto de partida explicações que tiveram sucesso em determinadas áreas (como é, indiscutivelmente, o caso da explicação baseada na seleção natural em biologia)? O que ganhamos em articular tais abstrações? Como, a partir dessas abstrações, podem-se obter explicações adequadas a determinados tipos de problemas, em áreas particulares? Que relação esses procedimentos têm com o uso de modelos e analogias nas ciências e na filosofia? A resposta a essas questões passam, a meu ver, por uma caracterização do raciocínio analógico e do papel que desempenha na atividade filosófica e científica. ${ }^{71}$

Um outro conjunto de questões poderia ser formulado quanto à inserção dos tópicos a que me dediquei neste artigo na ampla e diversificada frente de investigação a respeito da evolução da cognição e do comportamento, animal e humano. A literatura a esse respeito tem cres-

${ }^{71}$ Em Abrantes (1999b) desenvolvo um modelo do raciocínio analógico nas ciências e venho tentando estendê-lo ao caso da geração de teorias selecionistas fora do âmbito biológico. Uma das distinções que considero relevantes para questionar a distinção que faz Bradie entre dois tipos de epistemologias selecionistas é entre analogias formais e materiais.

Revista de Filosofia, Curitiba, v. 16 n.18, p. 11-55, jan./jun. 2004. 
cido exponencialmente nas últimas décadas e há diferentes abordagens, muitas vezes conflitantes, sendo desenvolvidas. Em algumas passagens desse artigo, indiquei relações do programa de uma epistemologia evolutiva com a chamada 'psicologia evolutiva', de um lado, e com a 'memética', de outro. Mas seguramente haveria ainda muito a ser dito com respeito ao amplo tópico da evolução da cultura, de suas relações com a evolução biológica e do lugar que haveria de aí ocupar a questão das origens e da dinâmica evolutiva do conhecimento (comum, científico, tecnológico, etc.).

Vejo as críticas e o grande número de questões deixadas em aberto não como indícios da precariedade do programa, mas, ao contrário, da sua vitalidade, da sua capacidade de, ao mesmo tempo, abalar algumas das nossas convicções e suscitar novas linhas de investigação. A tarefa é, contudo, tão fabulosa, que o tom escolhido por Dennett para descrevê-la é bastante adequado:

"Era uma vez um tempo em que não havia mente, nem significado, nem erro, nem função, nem razão, nem vida. Agora existem todas essas coisas maravilhosas. Deve ser possível contar uma história sobre como todas elas vieram à existência; e deve ser uma história de como, com sutis acréscimos, passou-se de elementos que claramente não possuíam essas propriedades maravilhosas, a elementos que claramente as possuem" (1995, p. 200). ${ }^{72}$

${ }^{72}$ Quero agradecer ao CNPq por uma bolsa de pesquisa que tem sido um grande incentivo para levar adiante esta pesquisa. Sou também grato aos vários colegas que se dignaram a comentar versões anteriores deste texto - cujos nomes omito para evitar esquecimentos constrangedores - e aos meus alunos, que tiveram de digerir versões por demais cruas do material que serviu de base para este texto. Quero também agradecer aos organizadores do III Simpósio Nacional de Filosofia da PUCPR, pela oportunidade de apresentar um primeiro esboço desse artigo, e aos seus participantes que, com suas críticas, levaram-me a reelaborar, em aspectos significativos, a versão que li na ocasião.

Revista de Filosofia, Curitiba, v. 16 n.18, p. 11-55, jan./jun. 2004. 


\section{Referências}

Abrantes, P. Naturalizando a epistemologia. In: Abrantes, P. (org.) Epistemologia e Cognição. Brasília: Editora da UnB, 1993.

. Naturalismo epistemológico: introdução. In: Évora, F.; Abrantes, P. (eds.) Cadernos de História e Filosofia da Ciência (CLE - UNICAMP), série 3, v. 8, n. 2, 1998, p. 7-26.

. Simulação e Realidade. Revista Colombiana de Filosofia da Ciência, v.1, n. 1, p. 9-40, 1999a.

. Analogical reasoning and modeling in the sciences. Foundations of Science, v. 4, n. 3, p. 237-270, 1999b.

. Problemas metodológicos em historiografia da ciência. Filho, Waldomiro (org.) Epistemologia e ensino de ciên cias. Salvador: Arcadia, 2002.

Abrantes, P.; Bensusan, Hilan Conhecimento, ciência e natureza: cartas sobre o naturalismo. In: Simon-Rodrigues, S. (ed.) Filosofia e Conhecimento: das formas platônicas ao naturalismo. Brasília: Editora da UnB, 2003, p. 273-333.

Bechtel, $\mathrm{W}$. Toward making evolutionary epistemology into a truly naturalized epistemology. In: Rescher, N. (ed.) Evolution, cognition and realism. NY: University Press of America, 1990, p. 63-77.

Bradie, M. Assessing evolutionary epistemology. Biology and Philosophy, v. 1, p. 401-59, 1986.

. Epistemology from an evolutionary point of view. In: Sober, E. (ed.) Conceptual issues in evolutionary biology. Cambridge (MA): The MIT Press, 1995, p. 453-75.

. The metaphysical foundation of Campbell's selectionist epistemology. In: Heyes, C.; Hull, D.L.(eds.) Selection theory and social construction. Albany: State University of New York Press, 2001, p. 5- 70.

Calvin, W.H. The cerebral symphony. NY: Bantam Books, 1990. 
Campbell, D.T. Evolutionary epistemology. In: Schilpp, P. (ed.) The Philosophy of Karl Popper (parte I). LaSalle (Illinois): Open Court, 1973, p. 413-463.

Cassini, Alejandro El problema heuristico en la epistemología evolucionista. Manuscrito, v. XXI, n. 2, 1998, p. 15-43.

Cziko, G. Without Miracles: universal selection theory and the second darwinian revolution. Cambridge (MA): The MIT Press, 1995. O texto citado neste artigo foi acessado pela Internet em 26/09/00. A paginação utilizada para identificar citações neste artigo é minha, com base no arquivo descarregado diretamente da página do autor (http:// faculty.ed.uiuc.edu/g-cziko/without_miracles/04.html).

. Universal selection theory and the complementarity of different types of blind variation and selective retention. In: Heyes, C.; Hull, D.L(eds.) Selection theory and social construction. Albany: State University of New York Press, 2001, p. 15-34.

Dennett, D. Why the law of effect will not go away. In: Dennett, D. Brainstorms. Sussex: Harvester Press, 1986, p. 71-89. Publicado originalmente em 1975.

. Darwin's dangerous idea: evolution and the meanings of life. NY: Simon \& Schuster, 1995.

Downes, Truth, Selection and Scientific Inquiry. In: Biology \& Philosophy, v. 15, n.3, p. 425-442, 2000.

Giere, R. Critical hypothetical evolutionary naturalism. In: Heyes, C.; Hull, D.L.(eds.) Selection theory and social construction. Albany: State University of New York Press, 2001, p. 53- 70.

Godfrey-Smith, P. Complexity and the function of mind in nature. Cambridge University Press, 1998.

Goldman, A. Epistemologia naturalista e confiabilismo. In: In: Évora, F.; Abrantes, P. (eds.) Cadernos de História e Filosofia da Ciência (CLE UNICAMP), série 3, v. 8, n. 2, 1998, p. 109-145.

Hahlweg, K.; Hooker, C.A. (eds.) Issues in evolutionary epistemology. Albany: State University of New York Press, 1989.

Revista de Filosofia, Curitiba, v. 16 n.18, p. 11-55, jan./jun. 2004. 
Heyes, C.; Hull, D.L.(eds.) Selection theory and social construction. Albany: State University of New York Press, 2001.

Hooker, C. Reason, regulation and realism. Albany: SUNY University Press, 1995.

Hull, D. In search of epistemological warrant. In: Heyes, C.; Hull, D.L(eds.) Selection theory and social construction. Albany: State University of New York Press, 2001, p. 155-167.

Kantorovich, A. Scientific discovery: logic and tinkering. Albany: State University of New York Press, 1993.

Kim, Kyung-Man Nested Hierarchies of Vicarious Selectors. In: Heyes, C.; Hull, D.L(eds.) Selection theory and social construction. Albany: State University of New York Press, 2001, p.101- 118.

Komblith, H. Knowledge and its place in nature. Oxford: Clarendon Press, 2002

Laland, K.; Brown, G. Sense and nonsense: evolutionary perspectives on human behaviour. Oxford: Oxford University Press, 2002.

Millikan, R. Language, thought and other biological categories. Cambridge (MA): MIT Press, 1984.

Munz, P. Philosophical darwinism: on the origin of knowledge by means of natural selection. London: Routledge, 1993.

Papineau, D. The evolution of knowledge. . In: Papineau, D. The roots of reason. Oxford: Clarendon Press, 2003, p. 39-82.

Plotkin, H.C. Darwin machines and the nature of knowledge. Cambridge (MA): Harvard University Press, 1997.

. The evolutionary analogy in Skinner's writings. In: Modgil, S.; Modgil, C. (eds.) B.F Skinner: consensus and controversy. New York: Falmer Press, 1987, p. 139-149.

Popper, K. A Lógica da pesquisa científica. SP: Cultrix, 1975.

Clarendon Press, 1972.

. Objective knowledge: an evolutionary approach. Oxford: The

Revista de Filosofia, Curitiba, v. 16 n.18, p. 11-55, jan./jun. 2004. 
. Conjecturas e Refutações. Brasília: Editora da UnB, 1982.

Richards, R. Natural selection and other models in the historiography of science. In: Brewer, M.B. et al. (eds.) Scientific inquiry and the social sciences: a volume in hon or of Donald T. Campbell. San Francisco: Jossey-Bass, 1981, p. 37-76.

Ruse, M. Levando Darwin a sério. BH: Itatiaia, 1995.

. On being a philosophical naturalist: a tribute to Donald Campbell. In: Heyes, C.; Hull, D.L.(eds.) Selection theory and social construction. Albany: State University of New York Press, 2001, p. 71-100.

. Does evolutionary epistemology imply realism? In: Rescher, N. (ed.) Evolution, cognition and realism. NY: University Press of America, 1990, p. 101- 110.

Stein, E. Getting closer to the truth: realism and the metaphysical and epistemological ramifications of evolutionary epistemology. In: Rescher, N. (ed.) Evolution, cognition and realism. NY: University Press of America, 1990, p. 119-126.

Thagard, P. Computational philosophy of science. Cambridge: The MIT Press, 1988.

Toulmin, S. The evolutionary development of natural science. American Scientist, v. 55, n.4, 1967, p. 456-71.

. Human understanding. Oxford: Clarendon Press, 1972.V. 1.

Wuketits, F.M. Evolutionary epistemology- a challenge to science and philosophy. In: Wuketits (ed.) Concepts and approaches in evolutionary epistemology. Dordrecht: Reidel, 1984, p. 1-33.

. The Philosophy of Donald T. Campbell: a short review and critical appraisal. Biology and Philosophy, v. 16, p. 171-188, 2001.

Recebido em 16/06/04 Aprovado em 04/08/04

Revista de Filosofia, Curitiba, v. 16 n.18, p. 11-55, jan./jun. 2004. 